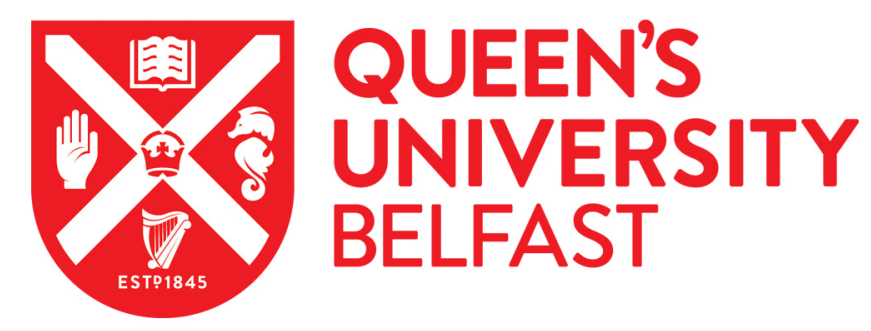

\title{
Using Inertial Measurement Units originally developed for biomechanics for modal testing of civil engineering structures
}

Hester, D., Brownjohn, J., Bocian, M., Xu, Y., \& Quattrone, A. (2018). Using Inertial Measurement Units originally developed for biomechanics for modal testing of civil engineering structures. Mechanical Systems and Signal Processing, 104, 776-798. https://doi.org/10.1016/j.ymssp.2017.11.035

Published in:

Mechanical Systems and Signal Processing

Document Version:

Peer reviewed version

Queen's University Belfast - Research Portal:

Link to publication record in Queen's University Belfast Research Portal

Publisher rights

(C) 2017 Elsevier Ltd.

This manuscript version is made available under the CC-BY-NC-ND 4.0 license http://creativecommons.org/licenses/by-nc-nd/4.0/,which permits distribution and reproduction for noncommercial purposes, provided the author and source are cited.

\section{General rights}

Copyright for the publications made accessible via the Queen's University Belfast Research Portal is retained by the author(s) and / or other copyright owners and it is a condition of accessing these publications that users recognise and abide by the legal requirements associated with these rights.

Take down policy

The Research Portal is Queen's institutional repository that provides access to Queen's research output. Every effort has been made to ensure that content in the Research Portal does not infringe any person's rights, or applicable UK laws. If you discover content in the Research Portal that you believe breaches copyright or violates any law, please contact openaccess@qub.ac.uk. 


\title{
Using Inertial Measurement Units originally developed for biomechanics for modal testing of civil engineering structures
}

\author{
David Hester ${ }^{\mathrm{a}}$, James Brownjohn ${ }^{\mathrm{b}}$, Mateusz Bocian ${ }^{\mathrm{c}}$, Yan Xu $^{\mathrm{b}}$, Antonino Quattrone ${ }^{\mathrm{d}}$ \\ aSchool of Natural and Built Environment, Queen's University Belfast, UK \\ ${ }^{b}$ Vibration Engineering Section, University of Exeter, UK \\ 'Department of Engineering, University of Leicester, UK \\ ${ }^{\mathrm{d}}$ Civil and Construction Engineering, Politecnico di Torino, Italy
}

\begin{abstract}
This paper explores the use of wireless Inertial Measurement Units (IMU) originally developed for bio-mechanical research applications for modal testing of civil engineering infrastructure. Due to their biomechanics origin, these devices combine a triaxial accelerometer with gyroscopes and magnetometers for orientation, as well as on board data logging capability and wireless communication for optional data streaming and to coordinate synchronisation with other IMUs in a network. The motivation for application to civil structures is that their capabilities and simple operating procedures make them suitable for modal testing of many types of civil infrastructure of limited dimension including footbridges and floors while also enabling recovering of dynamic forces generated and applied to structures by moving humans. To explore their capabilities in civil applications, the IMUs are evaluated through modal tests on three different structures with increasing challenge of spatial and environmental complexity. These are, a full-scale floor mock-up in a laboratory, a short span road bridge and a seven story office tower. For each case, the results from the IMUs are compared with those from a conventional wired system to identify the limitations. The main conclusion is that the relatively high noise floor and limited communication range will not be a serious limitation in the great majority of typical civil modal test applications where convenient operation is a significant advantage over conventional wired systems.
\end{abstract}

Keywords: Operational Modal analysis; Wireless sensors; Ambient vibration; Civil engineering structures.

\subsection{Introduction}

The conventional view of civil infrastructure health monitoring is an array of permanently installed instrumentation with continuous data acquisition and data interpretation. Such structural health monitoring (SHM) systems are usually deployed on new landmark structures, with practically every new long suspended span bridge design including permanent instrumentation. There is an argument that such large structures will not benefit from SHM until they begin to age and that resources would be more effectively deployed on a larger number of smaller, older, but still critical infrastructure components such as the many masonry arch bridges and viaducts built in Victorian Britain. The large number of these older structures (e.g. tens of thousands of bridges in the UK) rule out comprehensive permanent monitoring, but there is a case for peripatetic monitoring systems for vibration and load testing. Such relocatable instrumentation arrays must be deployable easily and rapidly. 
Short term instrumentation typically comprises strain gauges and/or accelerometers [1]. Strain gauges are primarily used for capturing static and quasi-static effects with accelerometers primarily capturing dynamic effects. In fact accelerometers are widely used for structural identification (St-id), which comprises system identification (modal analysis) designed to validate numerical models and to understand and predict dynamic performance [2]. Accelerometers deployed in civil infrastructure St-id applications have traditionally been large wired devices using piezo-electric sensing elements or servo-control of a proof mass. Requirements from a wide range of user communities have driven development of micro electrical mechanical system (MEMS) accelerometers that are small, light, inexpensive and low power. The potential to deploy MEMS accelerometers for civil infrastructure SHM applications has led to a large volume of research in smart wireless accelerometers for longterm deployment. Most such sensors have been designed and deployed by the research community, with exemplar applications such as the large scale Imote2 deployment on Jindo Bridge [3]. While most SHM research has gone on long term deployments of wireless sensors, few deployments focus on short term investigations [4]. Also, while there are many commercial solutions for wireless sensing of non-dynamic data there are fewer commercial wireless accelerometers. These are generally optimised applications such as in automotive and aerospace engineering where acceleration ranges are relatively large compared to the sub- $1 \mathrm{~g}$ ranges experienced in operational monitoring of civil infrastructure such as bridges and buildings.

Accelerometers have been used in the biomechanics community for many years e.g. for gait analysis [5]. Inertial measurement units (IMUs) were developed with incorporation of gyroscopes [6] and magnetometers, and were subsequently available for wireless data acquisition [7]. Demand from the biomechanics community with applications in health and sport have driven development of commercial systems that are used in short term in-vivo instrumentation e.g. for hospital outpatient diagnosis, movement science experiments and for study and enhancement of sports performance. These systems both complement and replace optics-based motion capture systems and may be used with force places and instrumented treadmills. The large rotations and translations involved require conversion to global (world) coordinate systems (WCS) but other than this, the requirements for size, weight, wireless communication and low power are remarkably similar to the requirements for vibration measurements of civil infrastructure. This was the experience of the authors when using biomechanics IMUs for tracking human movements in open space as part of research on vibration serviceability of footbridges [8].

Problematic footbridge vibrations occur at frequencies $(0.5 \mathrm{~Hz}$ to $5 \mathrm{~Hz})$ consistent with the frequency range of biomechanics applications, the footbridge vibration levels are well above the sensors' resolution levels and noise floors, and footbridge spans do not usually exceed the range limits for wireless transmission.

The typical civil field applications are time-constrained, logistically demanding and with restricted access for cabling. Hence a system that is readily transported, can be deployed rapidly and does not need cables is a very attractive proposition. The research described here aimed to find out if the limited resolution would be a show stopper for application in less lively structures such as tall buildings and road bridges.

This paper begins by describing how wired and wireless sensors are traditionally used for vibration testing, noting their strengths and limitations. A detailed comparison of performance IMUs with a 
wired system is described for the floor mockup, followed by description of applications to a short span highway bridge and a nine-storey university building.

\subsection{Wired accelerometer systems in modal testing of civil infrastructure}

While only a single accelerometer is needed to estimate modal frequencies and damping ratios, full description of modal properties additionally requires estimation of mode shapes and modal masses, two properties frequently combined in the form of scaled mode shapes. Estimation of the full set of modal properties such as in ground vibration testing of aircraft [9] and vibration serviceability evaluation of lively floors in offices and hospitals [10] requires measurement of excitation force usually due to one or more shakers and acceleration response at multiple locations in a modal test [11]. Various techniques of experimental modal analysis (EMA) are applied to recover the modal properties and these require the force and response signals to be synchronised, since the identification processes rely on phase relationships between and among force and response signals.

Where a force signal cannot be provided or cannot be measured, output only or ambient vibration testing is used, and a range of techniques of operational modal analysis (OMA) are applied to recover all modal properties with the exception of modal mass or mode shape scaling. Typical applications of OMA include long span bridges [12], towers, chimneys [13] and tall buildings [14]. The requirements of synchronous measurement of all response signals also apply.

Wired systems have varied architecture, with a large range of multichannel acquisition and analysis systems to choose from. The front end of such systems is nowadays typically a simultaneous sample and hold buffer to capture all signals at the same time instant, feeding a 24 bit analog digital converter which means that little or no signal amplification is required due to having bit-level precision below the sensor noise floor. With wired systems, choice of accelerometer and corresponding power supply signal conditioning allows for optimisation to application using high resolution sensors such as the PCB piezo-electric [15], Honeywell Quartz-Flex [16]or Kinemetrics servo- accelerometers [17]. An alternative to comprehensive signal analysis systems, bespoke systems built from multi-channel acquisition front ends in a component system (e.g. National Instruments) allow for flexible architecture providing signals for processing using separate modal analysis software.

\subsection{Wireless sensing for civil engineering structures}

The past two decades have seen significant effort on developing wireless sensing systems for civil engineering structures, especially bridges. This effort has been largely motivated by the logistical difficulties experienced when installing wired systems, however developments have been targeted at permanent monitoring systems rather than temporary systems. Hence wireless accelerometers developed and adapted by civil engineering researchers [18-20] have been optimised for low power operation with efficient real time data transmission and on board processing to reduce power requirements and the need for downstream data reduction. The ultimate wireless accelerometer demonstration is the Jindo Bridge project [21]. There are few applications of such wireless accelerometers for short term measurement campaigns such as modal testing $[22,23]$ because their optimisation for long term monitoring and on-board processing means they are not well suited for the demands of a modal testing campaign. 
While modal testing requires synchronous data acquisition, this does not necessarily mean that data must be transmitted to a base station for analysis in real time. Hence a system of autonomous recorders conventionally deployed in seismic monitoring, and with GPS synchronisation can be used for distributed data acquisition with data from separate units merged in post processing for modal analysis. Systems from Guralp and GeoSIG provide this capability and the latter was deployed for ambient vibration testing of Humber Bridge in 2008 [24]. In the absence of a GPS signal, precision clocks can be used to synchronise recorders [25-27] but these are usually for high-end applications, and there is justification for low-cost devices with limited capabilities and simple operation in certain circumstance. The aim of this paper is to show the capabilities and limitations of such a system.

\subsection{Objectives}

Wireless sensor systems for civil engineering structures have been optimised for long term monitoring and real time data transmission to a base station e.g. Imote2 [19]. For modal testing with tight timing and logistical constraints the time spent establishing a wireless network for real time transmission is not a good investment when reliable synchronous data collection is all that is needed. It is capability and performance in this respect that is investigated in this paper, as modal tests need to be time-efficient with easy to deploy accelerometers. Authors have found that a modal test (of a footbridge) can be reduced to carrying a handful of IMUs to site in a coat pocket, resting them on the bridge surface at selected measurement points for set duration then collecting the IMUs and returning to base. Subsequent downloading and merging of data from each IMU is equally simple. This paper explores the limits of capability of a particular type of IMU designed for biomechanics applications when used for modal testing of a representative set of civil structures.

Identifying capabilities and limitations will build confidence in using the IMUs for modal testing of specific structures by comparison with high resolution wired accelerometers, focusing on synchronisation and resolution. To begin, the IMUs and wired (reference) sensors are described in section 2, then the ability of the IMUs to capture the mode shapes is examined for three different structures: a laboratory floor structure $(5 \mathrm{~m} \times 7.5 \mathrm{~m})$ ), a steel road bridge ( $36 \mathrm{~m}$ span), and a 7 story concrete office building. These results are reported in sections 3,4 and 5 respectively. It is shown that broadly speaking the frequencies and mode shapes obtained from the IMUs agreed very well with those obtained from the wired system.

\subsection{Description of wired and wireless sensors used}

\subsection{Wired accelerometers: Honeywell QA-750 force balance accelerometers}

The reference accelerometers used here are Honeywell QA-750 quartz-flex force balance accelerometers. These are inertial grade uniaxial accelerometers historically used for inertial guidance (aerospace) and directional drilling (oil/gas industry). Their low noise floor and frequency response to DC has allowed their successful use for many years for the modal testing of a range of civil engineering structures. They are also used in the structural health monitoring systems installed on Hong Kong's long span bridges [28]. These accelerometers comprise a sprung proof mass moving in a magnetic coil whose current, generated by a servo-controller keeps the mass in position. For field testing described in this paper the current signal is dropped across an external $1 \mathrm{k} \Omega$ resistor so that effective scale factor is approximately $1.3 \mathrm{~V} / \mathrm{g}$ and using a 24 bit analogue to digital converter (ADC) with $\pm 5 \mathrm{~V}$ range, bit level resolution is $0.155 \mu \mathrm{g}\left(1.52 \mu \mathrm{m} . \mathrm{s}^{-2}\right)$. The accelerometer is mounted in 
a perspex housing shown in Fig. 1 . This may be attached to a structure using glue or magnets, but more usually the housing is attached to a base plate with three levelling screws (Fig. 1) that rest on the horizontal surface of a structure whose vibration levels are usually a small fraction of gravity. The stiff mounting has no effect on the performance of the QA in the range of frequencies measured on civil structures.

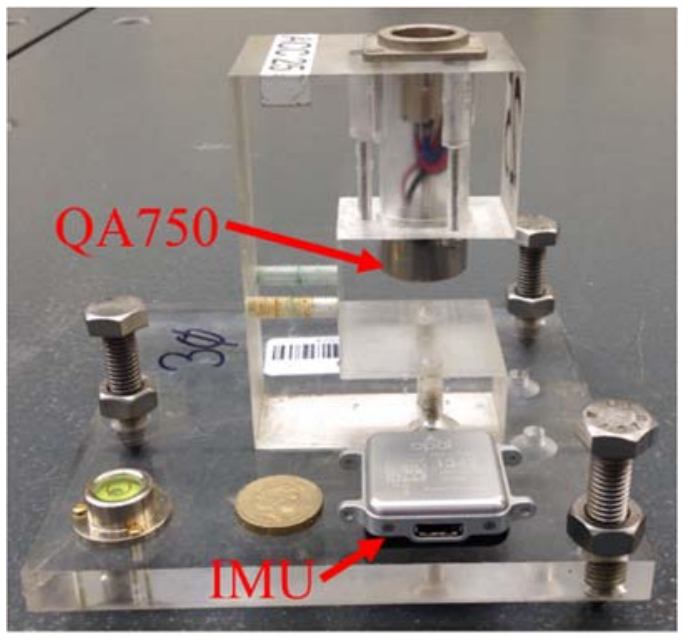

Fig. 1, Honeywell QA 750 accelerometer mounted in perspex housing with Opal IMU left on the base plate.

\subsection{Wireless accelerometers (IMUs)}

The IMU used here is the APDM Opal ${ }^{\mathrm{TM}}$ shown in Fig. 1 placed on the perspex base plate of the QA750 accelerometer. For size reference, a $f 1$ sterling coin is also shown in the figure.

IMUs were originally developed for clinical research in biomechanics [29] and the fusion of data from three types of sensor promotes them to Attitude and Heading Reference Systems (AHRS). The Opal is one type of AHRS described in [29]. The on board magnetometer, triaxial accelerometer and triaxial gyroscope provide data on motion and orientation. Each Opal IMU also incorporates a temperature gauge, flash memory, and communication managed by an on-board microcontroller. In this study vertical and biaxial horizontal acceleration with respect to the local coordinate system of the IMU are used and the gyro and magnetometer data are not needed to transform accelerations to WCS. With the 14-bit ADC the $\pm 2 \mathrm{~g}$ and $\pm 6 \mathrm{~g}$ ranges offered correspond to bit-level resolution of $240 \mu \mathrm{g}\left(2.35 \mathrm{~mm} . \mathrm{s}^{-2}\right)$ and $730 \mu \mathrm{g}\left(7.19 \mathrm{~mm} . \mathrm{s}^{-2}\right)$. For all the measurements described here the sample rate was set to $128 \mathrm{~Hz}$ per channel.

Of great importance to the performance of any compound (e.g. multi-agent/unit) wireless measurement system is the capability for synchronised data capture. Opal ${ }^{\mathrm{TM}} \mathrm{IMUs}$ are synchronised in one of two ways, either with or without a wireless access point allowing rapid data streaming to the host computer. In the former mode, denoted as a synchronised streaming mode (SSM), any deviations in the timing of data collected by IMUs are adjusted to the master time of the host computer. Due to its dependence on access point connectivity, SSM is suitable for laboratory environments of relatively small dimensions. In the latter mode, denoted as synchronised logging 
mode (SLM), the timing of data capture is adjusted according to a probabilistic model, based on a network of individual clocks of all units. The data are recorded onto the memory of each unit and downloaded offline via a docking station. SLM is suitable for applications in which immediate data accessibility is not of critical importance.

When operating in SSM the IMUs need to remain within $30 \mathrm{~m}$ of the wireless access point to maintain synchronisation. Definite information on the maximum distance between IMUs allowing synchronisation to be maintained when operating in SLM is not available. Essentially, having been developed for applications in biomechanical research, situations where the IMU were tens of meters apart were unlikely to occur. In this study the sensors will be used in SLM as the requirement to set up a wireless access point on a civil engineering structure is logistically undesirable. In SLM if the IMU's are out of range with each other they each keep time using their own internal clock. Once this occurs, some drift is possible between individual sensors, with larger drifts likely if there are large temperature ranges among sensors. Synchronisation drift is an important issue as it can affect modal analysis procedures [30], but because wireless communication and synchronisation effects on modal analysis are affected by a very wide range of factors it is not studied here. Instead the aim is to examine if the potential errors identified above are sufficiently small that the mode shapes obtained based on data from IMUs are still identified correctly.

As part of a previous study [31] it was shown that IMU's could be used to capture the mode shapes of a relatively flexible cable supported footbridge. However, significant questions remained as to how the IMUs would perform on more common civil engineering structures such as road bridges and office towers, where the amplitudes of vibration will be significantly smaller than on a cable supported footbridge and synchronisation between sensors could be affected by larger distances and physical barriers such as walls/floors between the IMUs. These questions are addressed in this current work.

\section{$\underline{2.3 \text { Sensor noise floor }}$}

Manufacturer data for the two sensors quotes sensor noise floor for the QA-750 as $7 \mu \mathrm{g} / \sqrt{\mathrm{Hz}}$ in 0-10 $\mathrm{Hz}$ band and for the Opal ${ }^{\mathrm{TM}}$ as $128 \mu \mathrm{g} / \sqrt{\mathrm{Hz}}$. A test of the sensors in quiet laboratory conditions was used to check these figures. In two separate exercises in different laboratories and times, signals from three co-located sensors were acquired. Any coherent response due to small vibrations in the quiet laboratory is filtered to leave non-coherent signals representing noise [32]. The result is shown in Fig. 2 . In both cases the self-noise is below the manufacturer specification and in fact the Opal self-noise, for the sensor operating in the $6 \mathrm{~g}$ range, is below the bit-level resolution. The Opal noise floor is 10 times greater than for the QA.

The effect of sensor noise floor on accuracy of modal identification is beyond the scope of this paper although recent research [33] has been able to quantify the effect of (response) signal to (sensor) noise ratio for Bayesian operational modal analysis. A pilot study [26] comparing IMUs and QA for ambient response of a footbridge has shown that the effect of IMU noise floor on frequency and damping estimation uncertainty in one specific application is insignificant. 


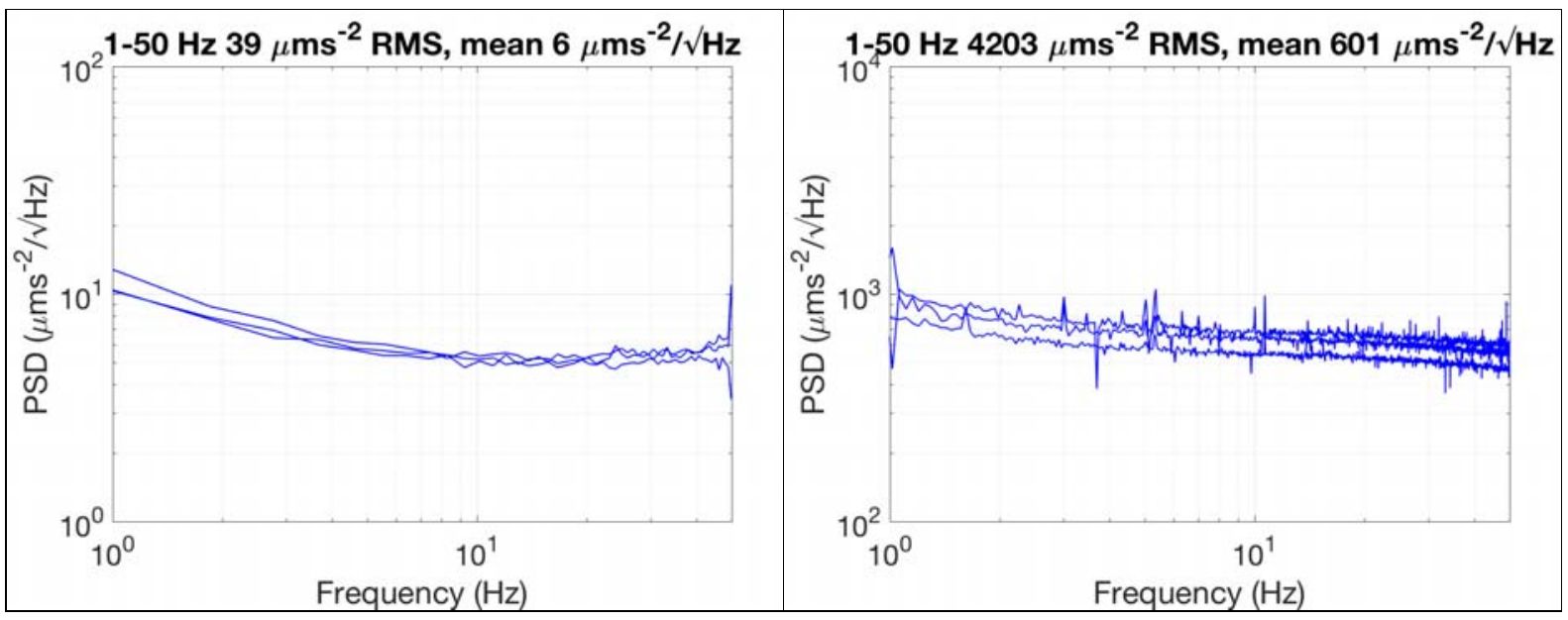

Fig. 2, Power spectral density of sensor self-noise for QA-750 (left) and Opal IMU (right).

\subsection{Laboratory Trial}

The laboratory trial was split into two parts. Initially both sensors (QA and IMU) were placed on a shaker to see how the IMU performed relative to the QA across a range of amplitudes and frequencies (section 3.1). Subsequently data from both sensors were used to calculate the mode shapes of a steel floor structure that was built in the laboratory (section 3.2). Essentially Section 3.1 checks the sensitivity/performance of the accelerometer in the IMU across the rage of acceleration amplitudes and structural frequencies typically encountered on civil engineering structures and section 3.2 checks if under laboratory conditions the synchronisation between the different IMUs in the network is sufficiently accurate to allow mode shapes to be recovered accurately.

\subsection{Performance of accelerometers when placed on shaker}

Authors' experience of using the QA is that it is both accurate and reliable and hence very well suited to the demands modal testing of civil structures, but there are occasions when the full capability is not required and the expense not justified. Also technology developments lead to lower cost MEMS sensors that approach or even exceed the performance of QAs, which are regarded by authors as the standard against which all other accelerometers are judged.

Accelerometer calibration is provided by the manufacturers. For the QAs the calibration certificates state current output in $\mathrm{mA} / \mathrm{g}$ which is converted to $\mathrm{V} / \mathrm{g}$ using precision $1 \mathrm{k} \Omega$ load resistors, while for the IMUs the signals are converted to $\mathrm{m}^{-2} \mathrm{~s}^{-2}$ by on board processor. In each case a simple check is obtained using the $1 \mathrm{~g}$ signal offset when measuring vertical acceleration. Using this methods, the set of five IMUs used in the experiment to generate Fig. 2 report gravity as $9.864 \mathrm{~m} . \mathrm{s}^{-2}$ with standard error $0.6 \%$ while the set of four QAs report gravity as 9.8305 with standard error $0.3 \%$.

To examine how well the IMU performed with respect to the QA both sensors were mounted on a shaker (see Fig. 3) and a white noise excitation signal was provided to the shaker. The IMU was operating in SLM. The test lasted for approximately 10 minutes (600 seconds) and the time series recorded by both accelerometers (scanning rate $128 \mathrm{~Hz}$ ) is shown in Fig. 4(a). The shaker was driven at a quarter of maximum force output to generate maximum accelerations in the region of $\pm 1 \mathrm{~m} / \mathrm{s}^{2}$ which is the typical range of accelerations encountered on civil engineering structures. Fig. 4(b) shows a zoomed in view of one second of acceleration data and it can be seen that there is good 
agreement between the signals from both accelerometers. The Welch method was used to calculate the frequency content of both signals in Fig. 4(a), with window length of 60 seconds, with no overlap, and the result is shown in Fig. 4(c). It can be seen in Fig. 4(c) and Fig. 4(d), which shows a zoomed in view between $4-5 \mathrm{~Hz}$ that the frequency content returned by both sensors is very similar. To further examine how closely the signal from the IMU matches the signal from the QA, the transfer function ( $T_{q o}(f)$, Eq. 1 ) and magnitude squared coherence $\left(C_{q o}(f)\right.$, Eq. 2$)$ between the $Q A$ and the IMU are calculated and the results are plotted in Figs. 4(e) and (f) respectively.

$T_{Q I}(f)=\frac{P_{I Q}(f)}{P_{Q Q}(f)}$

$C_{Q I}(f)=\frac{\left|P_{I Q}(f)\right|}{P_{Q Q}(f) P_{I I}(f)}$

where $\mathrm{P}_{\mathrm{IQ}}$ is the spectral density of the QA signal and the IMU signal, $\mathrm{P}_{\mathrm{QQ}}$ is the power spectral density of the QA signal, and $P_{\|}$is the power spectral density of the IMU signal. For both metrics $\left(T_{Q_{1}}(f) \& C_{Q 1}(f)\right.$ ) values of close to one indicates a good match between the signals being analysed. Broadly speaking the plots in Figs. 4(e) and (f) remain close to one in the frequency range $0-20 \mathrm{~Hz}$, with just the transfer function falling slightly below one for higher values of frequency. This indicates that for frequencies in the range $10-20 \mathrm{~Hz}$ the IMUs may be slightly less accurate than the QAs however, overall the IMU compares very well with the QA. To examine if the amplitude of the acceleration signal affected the performance of the IMU (with respect to the QA) similar tests were performed at $50 \%$ and $75 \%$ of full shaker force output, leading to acceleration signals with amplitudes of $\pm 2 \mathrm{~m} / \mathrm{s}^{2}$ and $\pm 3 \mathrm{~m} / \mathrm{s}^{2}$ respectively. Plots almost identical to those shown in Fig. 4 were obtained, with the only difference being that the transfer functions for higher amplitude acceleration signals decline more gently than shown in Fig. 4(e). Essentially for larger amplitudes of acceleration the IMUs provide a performance even closer to the performance of the QA. This is to be expected, the higher sensor noise of the IMU (see section 2) becomes less of an issue for higher values of acceleration.

For the vast majority of floors and footbridges vibration serviceability is not a problem. However, for a small subset of these structures users report vibration serviceability issues, and modal tests are often commissioned by the structure owner. The experience of the authors in doing these kinds of modal tests is that signal levels of $\sim \pm 1 \mathrm{~m} / \mathrm{s}^{2}$ and frequencies of $0-20 \mathrm{~Hz}$ are fairly typical of these 'lively' footbridges and floors and in these applications the accelerometer in the IMU works well. However, capabilities at lower signal levels and to identify mode shapes remain to be tested, and these will be examined in subsequent sections. In particular IMUs must also remain accurately synchronised for the duration of the test so that modal analysis algorithms can work [30]. The ability of the IMU network to remain synchronised in laboratory conditions is examined in the next section where IMUs are used to determine the mode shapes of a laboratory floor structure having relatively high natural frequencies. 


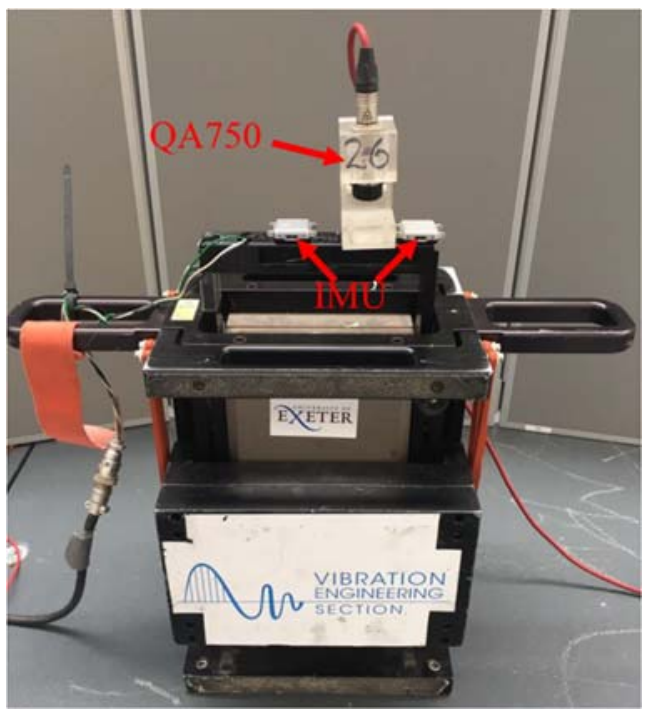

Fig. 3, IMU and QA on shaker.

(a)

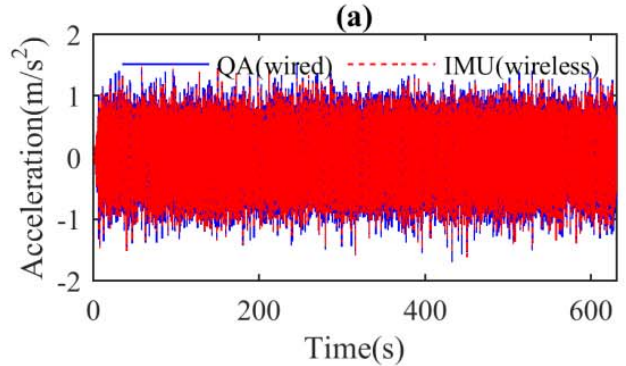

(c)

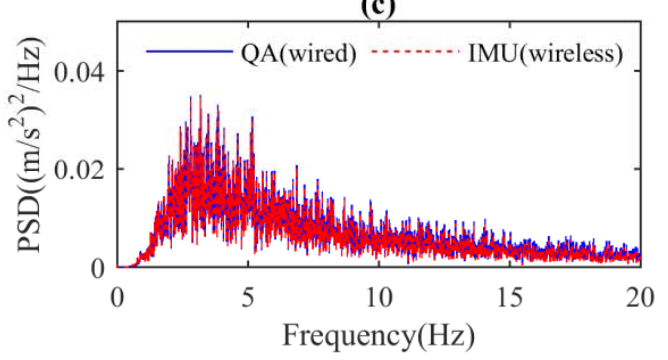

(e)

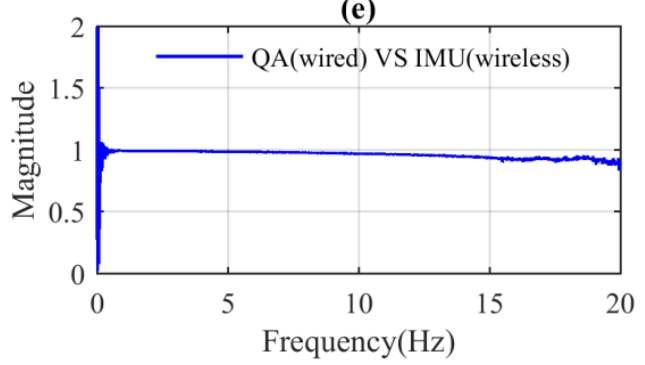

(b)

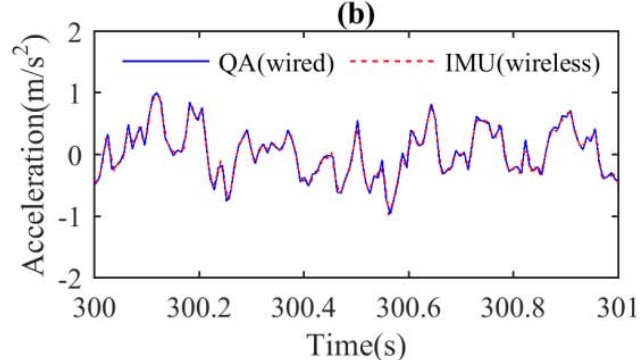

(d)

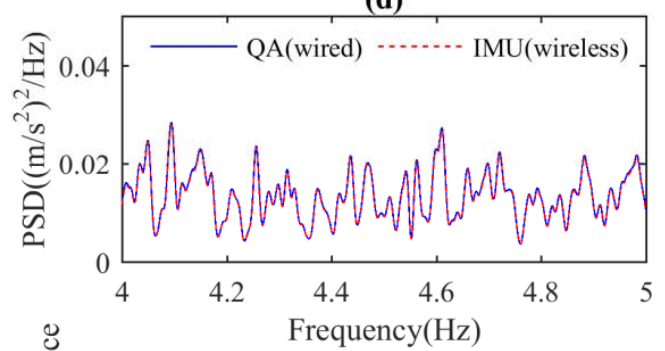

(f)

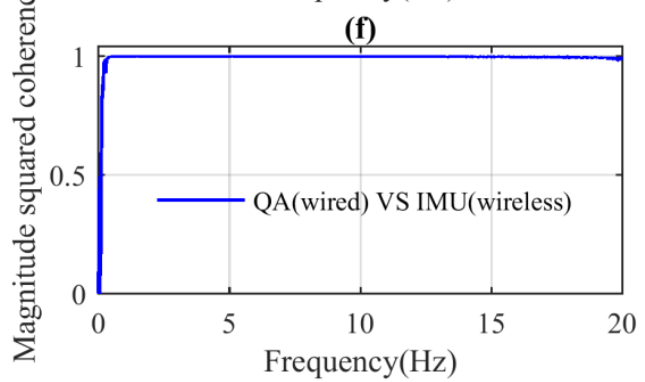

Fig. 4, results from shaker test (a) full time history (b) zoomed in view on a portion of the time series, (c) frequency content of time series shown in (a), (d) zoomed in view of frequency content, (e) Transfer function between QA and IMU, (f) Magnitude squared coherence between QA and IMU. 


\section{$\underline{3.2 \text { Modal test of floor structure }}$}

\subsubsection{Experimental setup for modal test on lab structure}

The test structure is the $5 \mathrm{~m} \times 7.5 \mathrm{~m}$ steel floor structure shown in Fig. 5 , the structure is supported only at the corners. The structure consists of a series of steel plates supported on steel beams. The two longitudinal beams (UB 475x191) span $7.5 \mathrm{~m}$ between the supports. The transverse beams (UB $305 \times 165)$ are $5.0 \mathrm{~m}$ long and they span between the longitudinal beams, these beams are indicated in Fig. 5. Finally an internal longitudinal beam (UC 203x203) spans between the two end transverse beams. This beam is under the slab and therefore is not visible in the figure. The slab is formed using $42 \mathrm{~mm}$ thick plates, and these span between the longitudinal beams. The plates are Sandwich Plate System (SPS) plates manufactured by Intelligent Engineering and consist of two metal plates bonded with a polyurethane elastomer core.

In total 35 test points were used in the modal survey, the test grid having 5 test points in the transverse location and 7 in the longitudinal direction. The position of the sensors' locations can be understood by examining the grid shown in Table 1. On the day of the test only 4 QA accelerometers were available so one accelerometer was left at TP 25 as a reference (circled in Fig. 5) and it remained in this location for the duration of the test. During the test one IMU was 'paired' with each one of the four QA's by simply leaving it on the base plate of the QA as shown in Fig.1, and all of the IMUs were operating in SLM. Then over the course of 12 swipes the 3 (roving) accelerometers roved to the remaining 34 points. For example the photo in Fig. 5 shows the position of the accelerometers for swipe 6 where the reference accelerometer is at test point 25 and the three roving accelerometers are at test points 6,13 and 20 respectively. For each swipe the structure was excited by a person doing a series of heel drops, typically six heel drops were carried out and each swipe took approximately 4 minutes to record. To excite as many modes as possible the person was standing at the centre longitudinally but slightly off centre transversely. The scanning frequency for both the QA and IMU sensors was $128 \mathrm{~Hz}$. The acceleration recorded at test point 25 due to two consecutive heel drops close to the centre of the floor structure is shown as an insert in the top left of Fig. 5. A zoomed in view of the first heel strike is shown in the insert in the top right of the figure and it can be seen that there is good agreement between the two signals.

Finally it should be noted that in a laboratory environment, while it is quicker to collect the data with the IMUs than with the QA's the difference is not so pronounced. This is because in the laboratory there is ready availability of power, there is no need to shelter the logging station, and we are free to run cables wherever we want. However, in the next section it is shown that when collecting data on a road bridge the IMU's prove vastly quicker/easier to use than the QA's. 


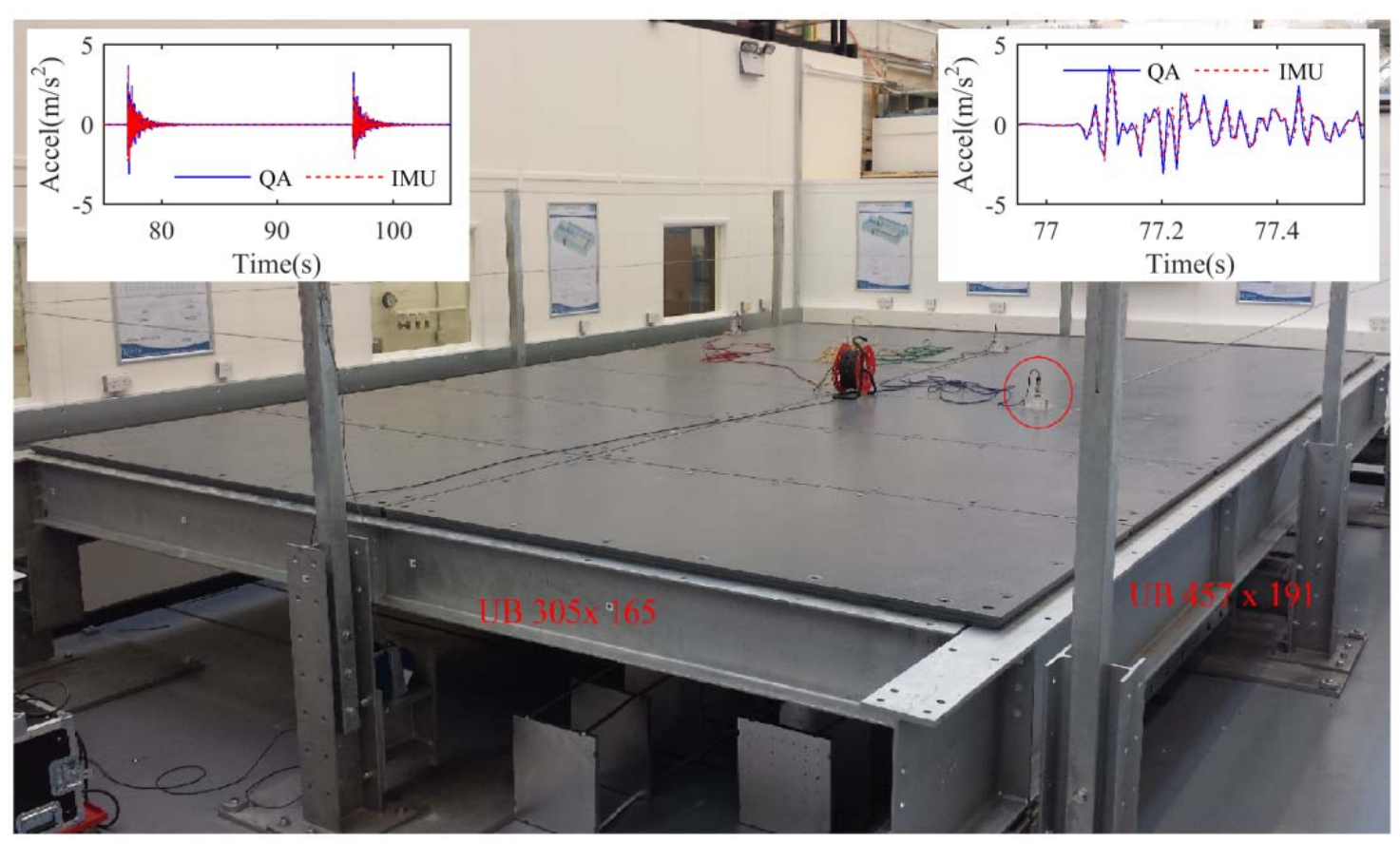

Fig. 5, Test floor structure in the laboratory and accelerometer locations for swipe 6 of the modal test.

\subsubsection{Modal identification procedure}

After the lab testing a sequence of twelve four-minute recordings were available for the QA data.

After the lab test the four IMU's were placed in the docking station and the data from the entire test were downloaded. Subsequently these data were split time-wise into twelve four-minute recordings corresponding to the twelve QA recordings. The modal analysis procedure used to identify the mode shapes in the QA and IMU data was exactly the same.

The method used is the NEXT/ERA operational modal analysis procedure [34]. This is one of several possible operational modal analysis procedures [35-37] and was used here due to long experience in its use and implementation in bespoke software [38]. NExT/ERA is now a standard procedure so only a very brief overview of the procedure as applied to these data is provided below.

Eigensystem Realization Algorithm (ERA) was put forward in the 1980's by Juang and Pappa [39] for modal idetnification. In their origional work Juang and Pappa applied ERA to free vibration response following random excitation of the structure using electro-dynamic shakers. By the mid 1990's there was a growing acceptance that conventional modal analysis techniques which required forced excitation were inappropriate for a number of structures, particularly civil engineering structures. Consequently James et. al. [40] proposed the Natural Excitation Technique (NExT) that allowed structures to be tested in their ambient environments. The NExT method works by calculating autoand cross-correlation functions of the ambient time histories. Subsequently these correlation functions are treated as if they were free vibration responses, to which it is possible to apply time domain identification schemes such as ERA. In later years, when using the NExT methodology many authors used ERA as the time domain identification scheme and consequently when discussing the NExT methodology it is often referred to as NExT/ERA. While NEXT/ERA is usually applied to ambient 
vibraton due to borad band random or near-random excitation (e.g. wind, road traffic), due to the origion of the technique it also works well with induced transient response. In fact the transient acceleration response to a heel drop resembles the auto/cross correlation time series generated by NExT.

Each of the twelve recordings was truncated to 200 seconds as five consecutive 40-second frames. For each swipe a $4 \times 4$ cross-spectral density (CSD) matrix was created using the Welch procedure [41] without overlap or windowing, resulting in twelve CSD matrices corresponding to the twelve swipes. Subsequently each of these CSD matrices were normalised with respect to the reference sensor by dividing each frequency line/layer of the CSD matrix by the auto-power of the reference sensor. This normalisation allows the twelve individual CSD matrices to be merged into a single $35 \times 35$ 'global' CSD matrix.

Using an inverse Fourier transform the global CSD matrix was transformed to time domain as impulse response functions (IRFs) for the ERA procedure for recovery of the modal properties. Based on this, a set of five modes is visible up to $32 \mathrm{~Hz}$. For both the QA and IMU data the NExT/ERA procedure produced a clean set of modes, which are presented in the next section.

\subsubsection{Results of test on lab structure}

Using the modal analysis approach described in section 3.2.2 the mode shapes and frequencies shown in Table 1 were obtained. It can be seen that mode shapes calculated from the IMU data agree very well with those calculated from the QA data. This indicates that the IMUs remained synchronised for the duration of this test. In addition, the level of damping calculated is a very good match between the QA and IMU sensors. This demonstrates that under laboratory conditions, where the IMUs remain relatively close together, data collected from them can be used to determine the mode shapes of the structure.

Rather than relying on a single numerical indicator such as modal assurance Criteria (MAC), we prefer visual inspection of the mode shapes which can reveal differences that MAC obscures. Inspection of Table 1 shows that all features of the mode shapes are identified equally well using the IMUs.

In a laboratory setting where IMUs maintain continuous wireless communication between each other gross synchronisation errors would be prevented so a short measurement is enough to check for minor errors of timing between the IMUs. These would have a proportional greater effect at higher frequencies so the good comparison of the highest frequency modes suggests that there is neither monotonic drift nor small timing variation of any consequence for modal identification when used for testing structures of this scale. However, before further conclusions can be drawn on the applicability of the IMU's for the modal testing of structures it is necessary to test them on real structures in the field. Conditions in the field may be more challenging, e.g. levels of vibration may be smaller and/or the conditions may be such that the sensors lose wireless contact and as a result may lose synchronisation. Therefore field tests on a steel road bridge and a seven story office tower were carried out and are reported in sections 4 and 5 respectively.

Table 1, Frequencies, damping coefficients and mode shapes for the first 5 vertical modes 


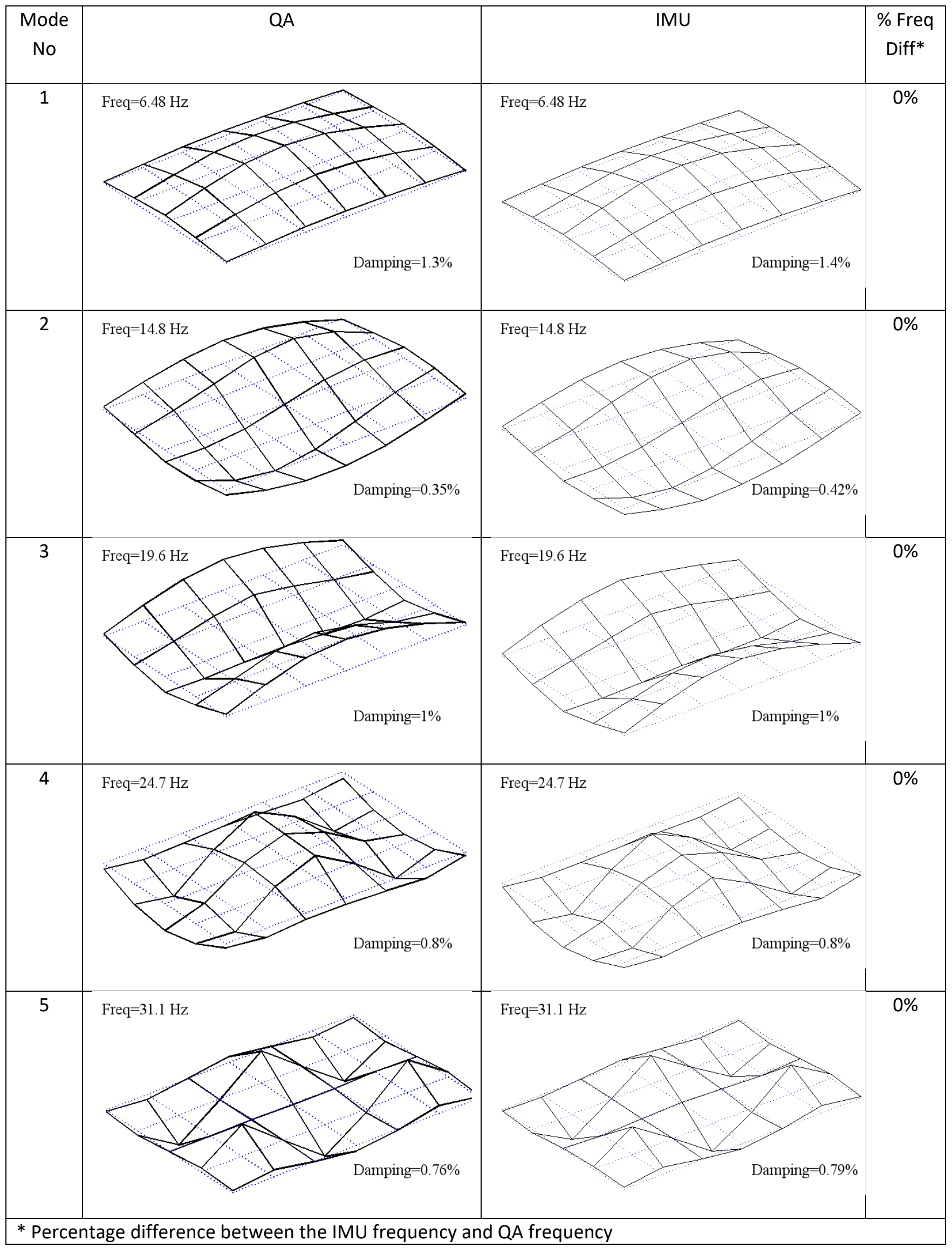




\subsection{Field test on steel road bridge}

\subsection{Description of bridge}

Fig. 6 shows the bridge used in this experiment and a plan view of the bridge is shown Fig. 7. The bridge is a half through steel girder bridge, it spans $36 \mathrm{~m}$ and the deck is simply supported. The $7.6 \mathrm{~m}$ wide, $200 \mathrm{~mm}$ deep, concrete deck is supported on a series of $450 \mathrm{~mm}$ deep steel beams spanning transversely between the main girders which are approximately $2 \mathrm{~m}$ deep.

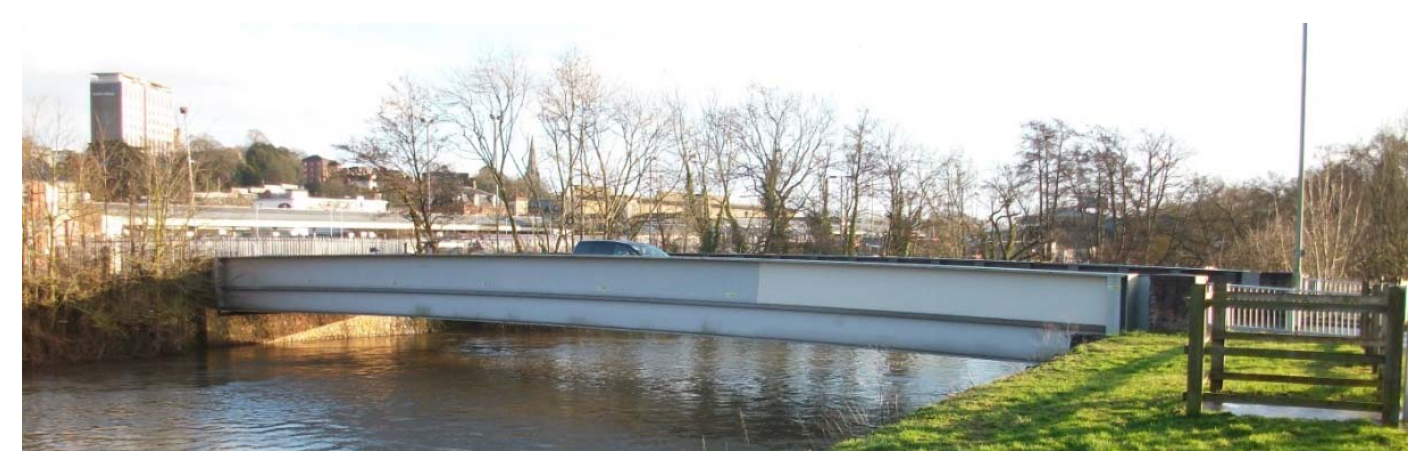

Fig. 6, Bridge used in field test.

\section{$\underline{4.2 \text { Collecting acceleration data }}$}

This section describes installing a conventional sensing system on a live bridge (section 4.2.1), and the procedure for installing wireless IMUs (section 4.2.2).

Using wired accelerometers in the field requires a logging station to be set up and wires installed to connect each sensor to the logging station. Conventional wireless systems described in section 1 still require a logging station but the sensors are connected wirelessly to the logging station for wireless streaming of the data. However, it is not uncommon to have to spend time finding the necessary uninterrupted lines of sight for the wireless system to work properly.

So in both a wired arrangement and a conventional wireless system there is (i) a logging station and (ii) a system to transmit data from the sensor to the logging station. The IMUs require neither (i) nor (ii) because the data is logged at source and synchronisation is implemented by the sensors communicating with each other to ensure time synchronisation. Not having to install (i) and (ii) makes collecting field data with the IMUs vastly easier. The wired test described in section 4.2.1 took one person several days to plan and four people one day to execute. Planning and executing the test with the IMU system (section 4.2.2) took one person approximately 1 day.

\subsubsection{Wired system (QAs)}

Fig. 7 shows a plan view of the bridge and the accelerometer locations used. Accelerometer locations $A, B$ \& $C$ were at the $1 / 4$ point, mid-span and $3 / 4$ point of the deck on the north side of the bridge, locations D-F were at the same longitudinal positions on the south side of the deck. The data logging tent was set up at the northwest corner of the bridge and this is indicated in the top left of the figure. The accelerometer at location B is shown in Fig. 8(c), the accelerometer is attached to the underside of the top flange via a magnet, and the signal is carried to the data logger via the cables 
visible in the image. A schematic of the route taken by the cables is indicated in Fig. 7. Carrying the signal from the sensors on the south side of the bridge to the logger was logistically difficult as it is necessary to run a cable under the bridge deck (along the abutment shelf) which is slow and risky to install when the bridge spans over a river. A view of the logging tent is shown in Fig. 8(a) and the logging equipment used is shown in Fig. 8(b). In total acceleration was recorded for approximately 45 minutes and Fig. 8(d) shows the typical acceleration response recorded at sensor location B as a car crossed over the bridge.

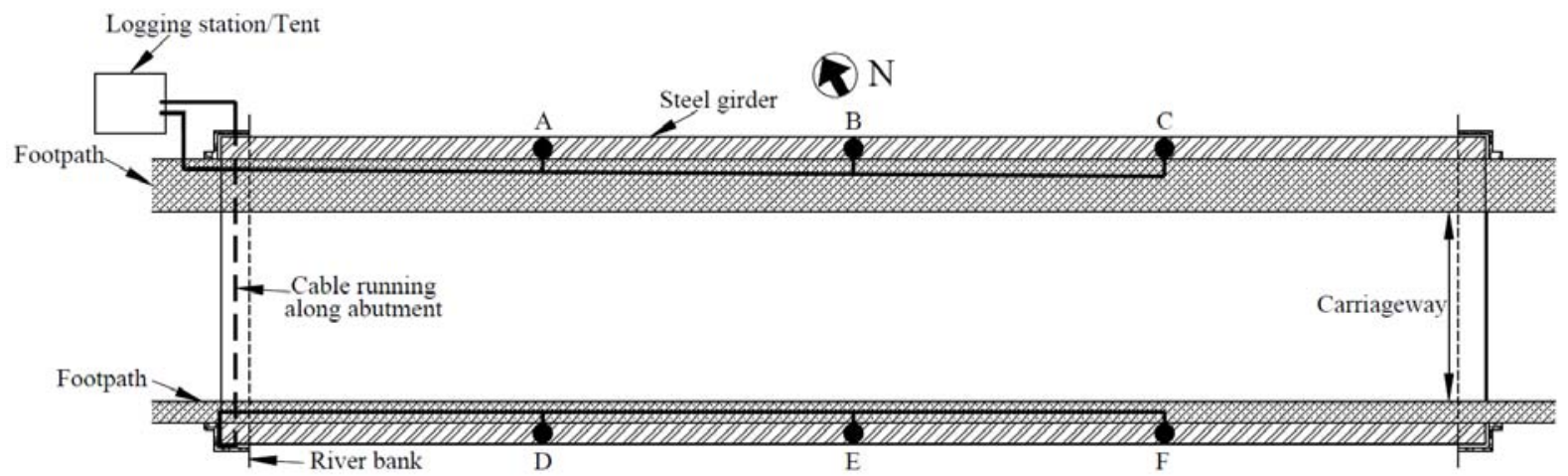

Fig. 7, schematic of the accelerometer locations A-F and corresponding cabling arrangement.

Carrying out the test described above takes a significant amount of time with most of the time being spent in the planning phase. The planning phase takes time because (1) installing cabling on a live bridge and erecting a logging station in a public area requires various health and safety permissions be applied for, and (2) the amount of equipment required to be brought to site (sensors, cabling, logging equipment, power source etc.) takes time to organise. But even once on site, setting up and demounting the equipment takes 3-4 people several hours. 


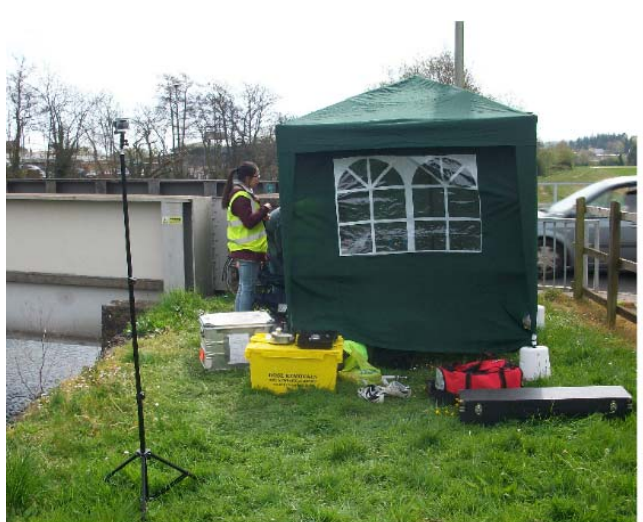

(a)

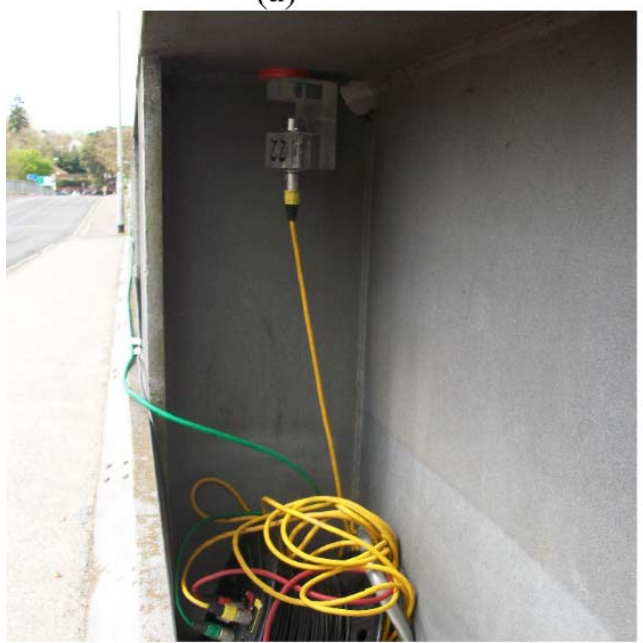

(c)

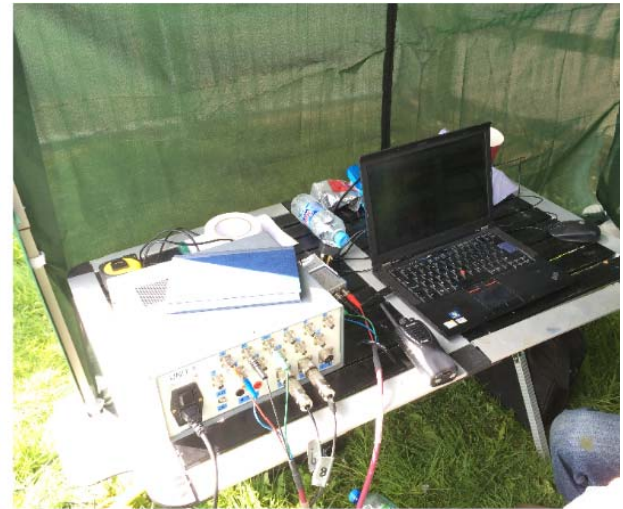

(b)

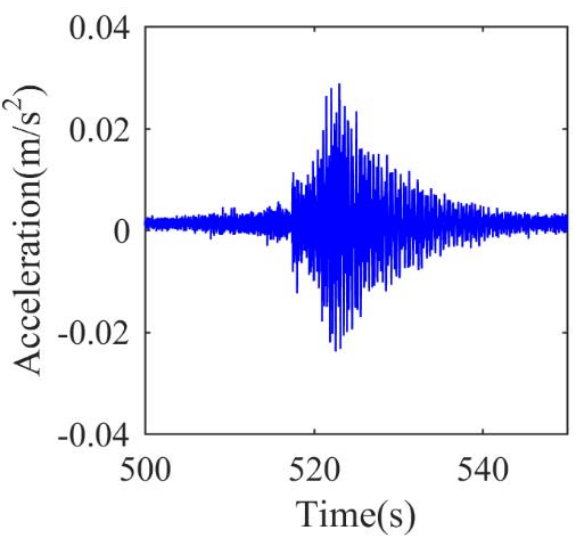

(d)

Fig. 8, Test set up for wired test (a) tent for data logging equipment positioned at northwest corner of bridge (b) logging equipment inside the tent, (c) accelerometer attached to underside of girder flange and associated cabling, (d) bridge acceleration response to a passing car

\subsubsection{Wireless system (IMUs)}

When collecting the data with the IMUs the same accelerometer locations (A-F in Fig. 7) were used. Fig. 9 shows the girder on the south side of the bridge and it can be seen that there is a horizontal steel member running along the length of the girder. The IMUs were attached to the bridge by taping them to this member, and a zoomed in view is shown in the insert of the figure. Mounting the IMUs adjacent to the vertical web stiffeners ensures the sensor is only picking up global bridge vibrations rather than local vibrations of the horizontal member. IMUs mounted at locations F, E \& D are indicated in the figure. Acceleration was recorded for 45 minutes and acceleration response recorded by the IMU at mid-span due to the passage of a car looked very similar to the signal shown in Fig. 8(d). As collecting the data with the IMU's essentially requires just 6 sensors to be mounted locally on the bridge the health and safety permissions are minimal, and therefore very quickly/easily obtained. The planning phase is practically non-existent as the only equipment required to be brought to site are six IMUs that can be carried in a coat pocket. Once on site one person can install and (once the test is complete) demount the sensors in approximately 10 and 5 minutes respectively. So relative to the man hours required to collect the data with a wired system collecting the data with the IMUs takes vastly less time. The mode shapes identified by both systems are presented in the next section. 


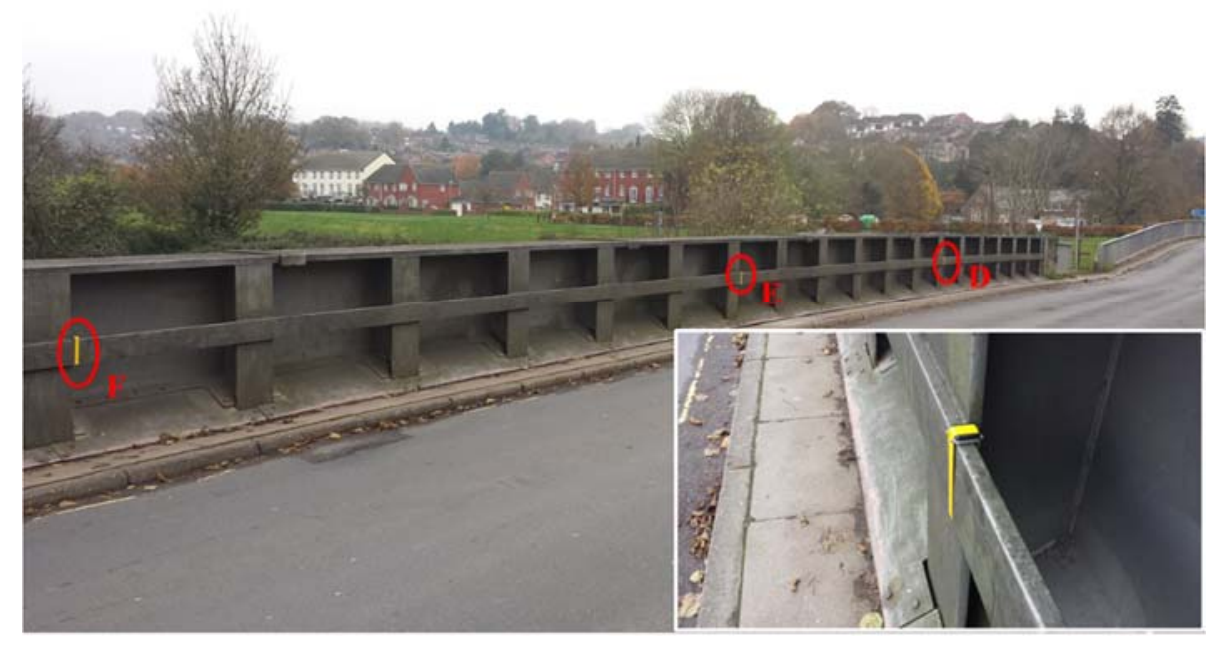

Fig. 9, IMUs deployed at sensor locations F, E \& D (see Fig. 7), insert shows how IMUs were simply taped to the horizontal member adjacent to the vertical web stiffener.

\subsection{Mode shapes from road bridge}

The modal identification procedure described in section 3.2.2 was implemented to identify the mode shapes from both the QA and IMU data and the results are shown in Table 2. Similar to the floor structure the mode shapes and frequencies calculated using the IMU sensors compares very well with those calculated using the wired QA system. There are some differences in the frequencies observed but it should be noted that the data for both systems were collected on different days and the day of the IMU test was colder, so some small differences in frequencies are to be expected [42]. The results shown in table 2 demonstrate primarily two things, firstly when the amplitude of acceleration is in the region of $\pm 0.1 \mathrm{~m} / \mathrm{s}^{2}$ or greater the IMUs will be able to capture the vibration. Secondly when contained in an open area $(18 \mathrm{~m} \times 9 \mathrm{~m})$ the IMUs remain sufficiently well synchronised to capture the mode shapes. This is believed to be because the distance between individual IMUs is sufficiently small that mesh synchronisation algorithm remains working. To further explore the capabilities of the IMUs for modal testing in the next section more challenging test environment is examined in the form of a 7 storey office tower. In the tower the vibrations are less than $0.1 \mathrm{~m} / \mathrm{s}^{2}$ and the IMUs will be separated by walls and concrete floors. 
Table 2, Frequencies and mode shapes for the first 5 vertical modes

\begin{tabular}{|c|c|c|c|}
\hline $\begin{array}{l}\text { Mode } \\
\text { No }\end{array}$ & QA & IMU & $\begin{array}{c}\% \text { Freq } \\
\text { Diff* }\end{array}$ \\
\hline 1 & $\begin{array}{l}\text { Freq }=3.1 \mathrm{~Hz} \\
\text { Damping }=1.7 \%\end{array}$ & Freq $=3.13 \mathrm{~Hz}$ & 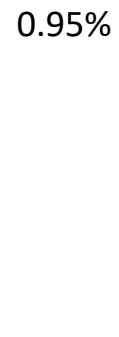 \\
\hline 2 & (2) & $\begin{array}{c}\text { Freq }=4.95 \mathrm{~Hz} \\
\text { Damping }=1.3^{\circ}\end{array}$ & $x^{2}$ \\
\hline 3 & 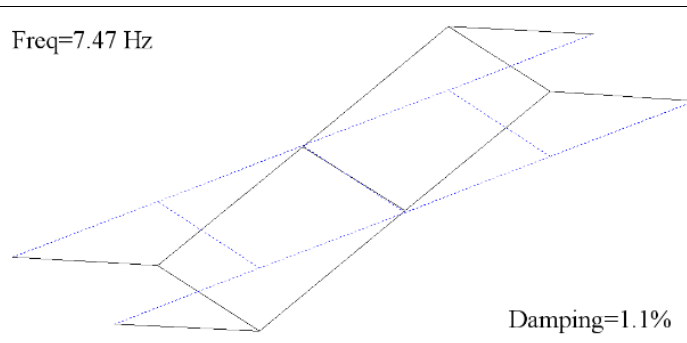 & + & . \\
\hline 4 & Damping $=1.9 \%$ & $\sqrt{2}$ & $1.77 \%$ \\
\hline 5 & 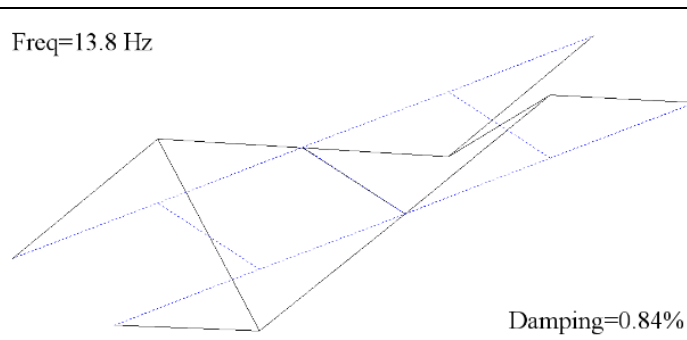 & 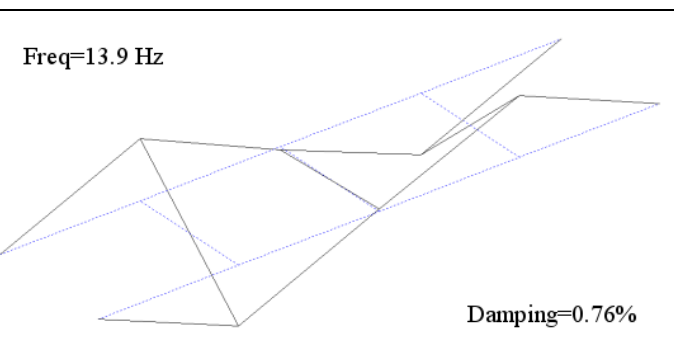 & $0.72 \%$ \\
\hline
\end{tabular}




\subsection{Field test on 7 storey concrete office tower}

\subsection{Description of tower}

The building used in the test is shown in Fig. 10. Structurally the tower is a little unusual in that floors 2-7 have slightly larger plan dimensions than the lower floors. This can be seen in Fig. 10 where the second floor overhangs the lower floors. The plan dimensions of floors $2-7$ is $22 \mathrm{~m} \times 16 \mathrm{~m}$ in the $\mathrm{x}$ and $\mathrm{y}$ directions respectively. For ease of visualisation horizontal $\mathrm{x}$ and $\mathrm{y}$ axes are indicated in the figure. In Fig. 10 it can be seen that the ground floor and first floor of the building are much longer in the y-direction. For the purposes of this test only tower vibrations are recorded, i.e. no data is recorded in other parts of the building. In total the tower has 10 floors, namely; basement, ground floor, first floor, mezzanine floor, second floor, and floors 3-7. For visualisation purposes a 3D schematic of the building is shown in Fig. 12 , however for simplicity, the overhang at the $2^{\text {nd }}$ floor is not indicated. Lateral stability for the tower is provided by a reinforced concrete stairwell and lift core. A schematic of the floor plan for floors 7, 5 and 3 are shown in Figs. 11(a-c) respectively.

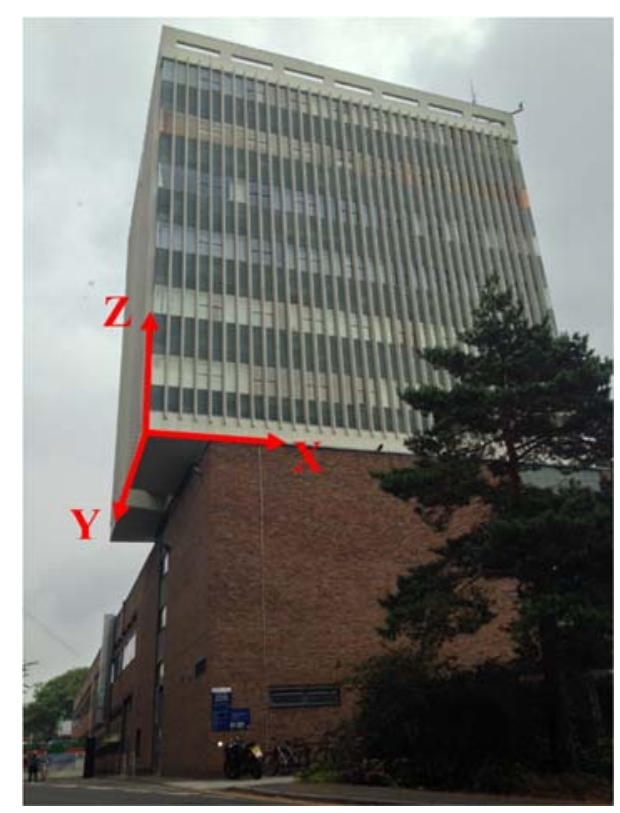

Fig. 10, Tower used in test.

\section{$\underline{5.2 \text { Collecting acceleration data }}$}

In this test acceleration is recorded four separate floors, namely floors 7, 5, 3 and the mezzanine floor and the location of the test points used on each floor are indicated in Fig. 11 using circular dots. The schematic in Fig. 11 does not show the room layout in the building (i.e. non-structural walls have been omitted) and as a result the irregular test points (on each floor) initially look a little odd.

However, on the night of the test the monitoring team did not have access to all parts of the building and therefore accelerometers had to be located where access was permitted. In total acceleration was recorded at fifteen different test points in the building labelled A-O in Fig. 11, four test points on each of floors 7, 5, and 3, and three test points on the mezzanine floor. 


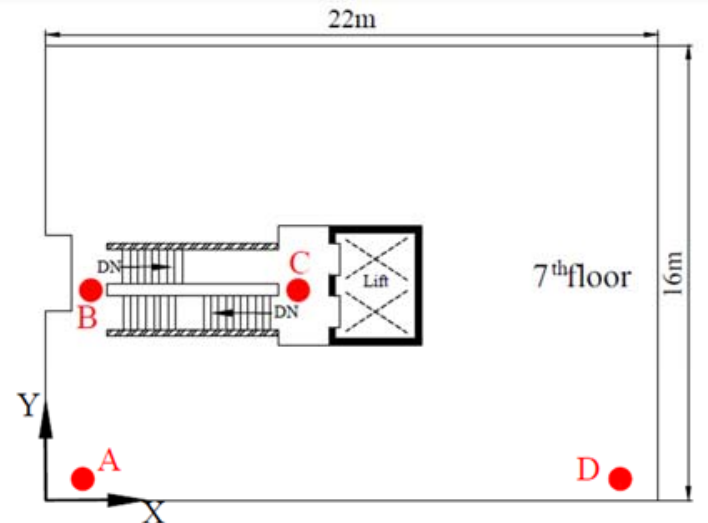

(a)

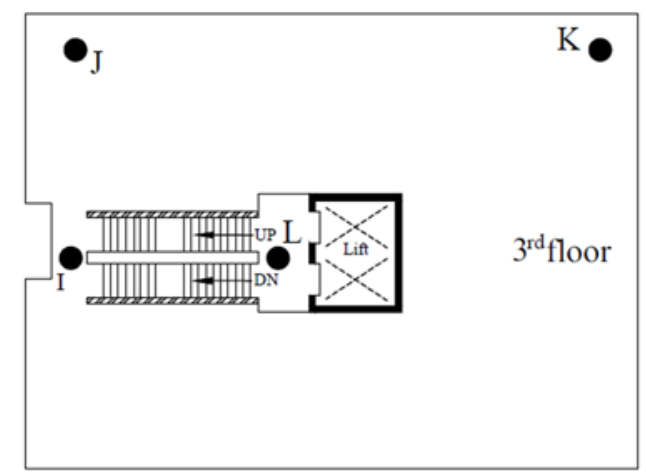

(c)

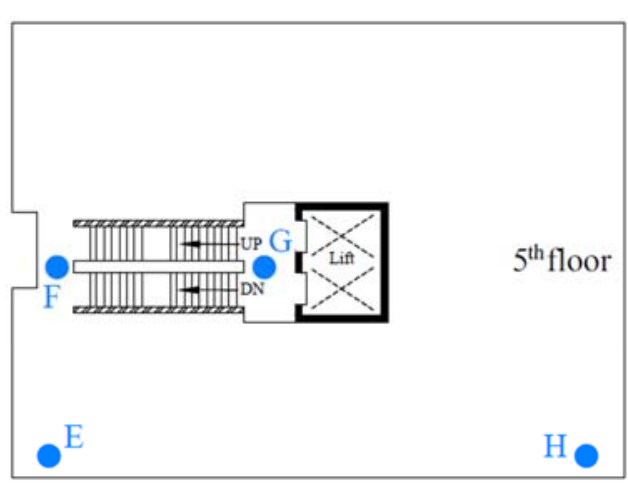

(b)

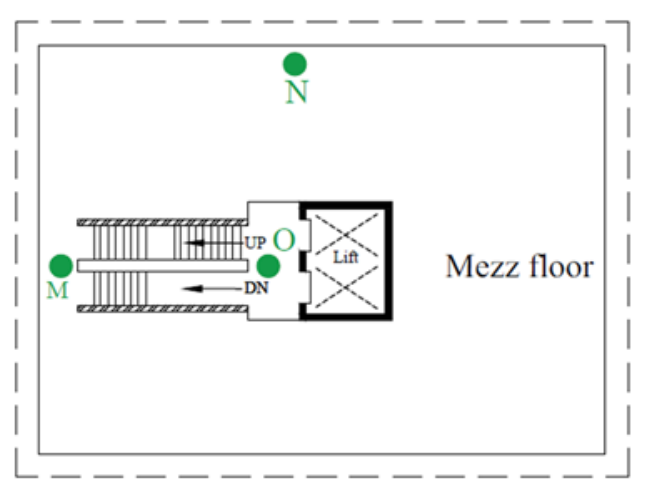

(d)

Fig. 11, schematic floor plans of the tower and test points used in modal test (a) $7^{\text {th }}$ floor, (b) $5^{\text {th }}$ floor, (c) $3^{\text {rd }}$ floor, (d) mezzanine floor.

Each test point required two QA accelerometers to measure acceleration in the $\mathrm{x}$ and $\mathrm{y}$ directions, and one IMU, (the IMU has a triaxial accelerometer so only one IMU is required per test point). Both the QAs and the IMUs were scanning at $128 \mathrm{~Hz}$ and the typical accelerometer arrangement at a test point is shown in Fig. 13(a). Due to the limited number of sensors available the data were collected in a number of 'swipes'. Table 3 gives a summary of the test points where acceleration was being recorded during a given swipe. It can be seen in the right hand column of Table 3 that test point $A$ is included in all four swipes, this is to allow the data from the different swipes to be 'glued' together in post processing. To allow a 3D visualisation of where test points A-O are located in the building the approximate positions of the test points on each floor are shown in Fig. 12. Test point $A$ on the $7^{\text {th }}$ floor is where the reference accelerometers are located.

Setting up the sensors for each swipe took in the region of 35-45 minutes and during each swipe acceleration was recorded for 24 minutes. In an effort to minimise any time drift in the IMU signals, just before the start of each swipe the five IMUs used in the test were brought together for at least two minutes to allow mesh synchronisation to occur, then they would be distributed to the test points for that swipe. Carrying out the test this way ensured that at least at the start of every swipe the IMUs were synchronised. The observed performance of the IMU's with respect to time drift is discussed in detail in the next section. For ease of cabling the logging station was set up on the $3^{\text {rd }}$ floor and is shown in Fig. 13(b). 
The fact that the QAs need a logging station means that cables need to be ran through peoples' offices and more problematically through public corridors and stairwells, to get the accelerometer signals to the logging station. Aside from the time it takes to, (a) install the cables, (b) secure them to minimise the trip hazard, and (c) remove them after the test. A significantly larger amount of time is spent preparing Health and Safety method statements and agreeing with the building operator safe routes for the cabling etc. For the IMUs (a)-(c) are simply not necessary, and as a result the time required to prepare and agree the method statements and risk assessments for a purely IMU test would only be a fraction of the time for the corresponding wired test.

Table 3, Test points in each of the four swipes

\begin{tabular}{|c|c|l|}
\hline $\begin{array}{c}\text { Swipe } \\
\text { No }\end{array}$ & $\begin{array}{c}\text { Floor where most of } \\
\text { the Test points are }\end{array}$ & $\begin{array}{l}\text { Test points in } \\
\text { the swipe* }\end{array}$ \\
\hline 1 & $7^{\text {th }}$ floor & A, B, C, D \\
\hline 2 & $5^{\text {th }}$ floor & A, E, F, G, H \\
\hline 3 & $3^{\text {rd }}$ floor & A, I, J, K, L \\
\hline 4 & Mezzanine floor & A, M, N, O \\
\hline *Test point where reference accelerometers \\
located is indicated in bold
\end{tabular}

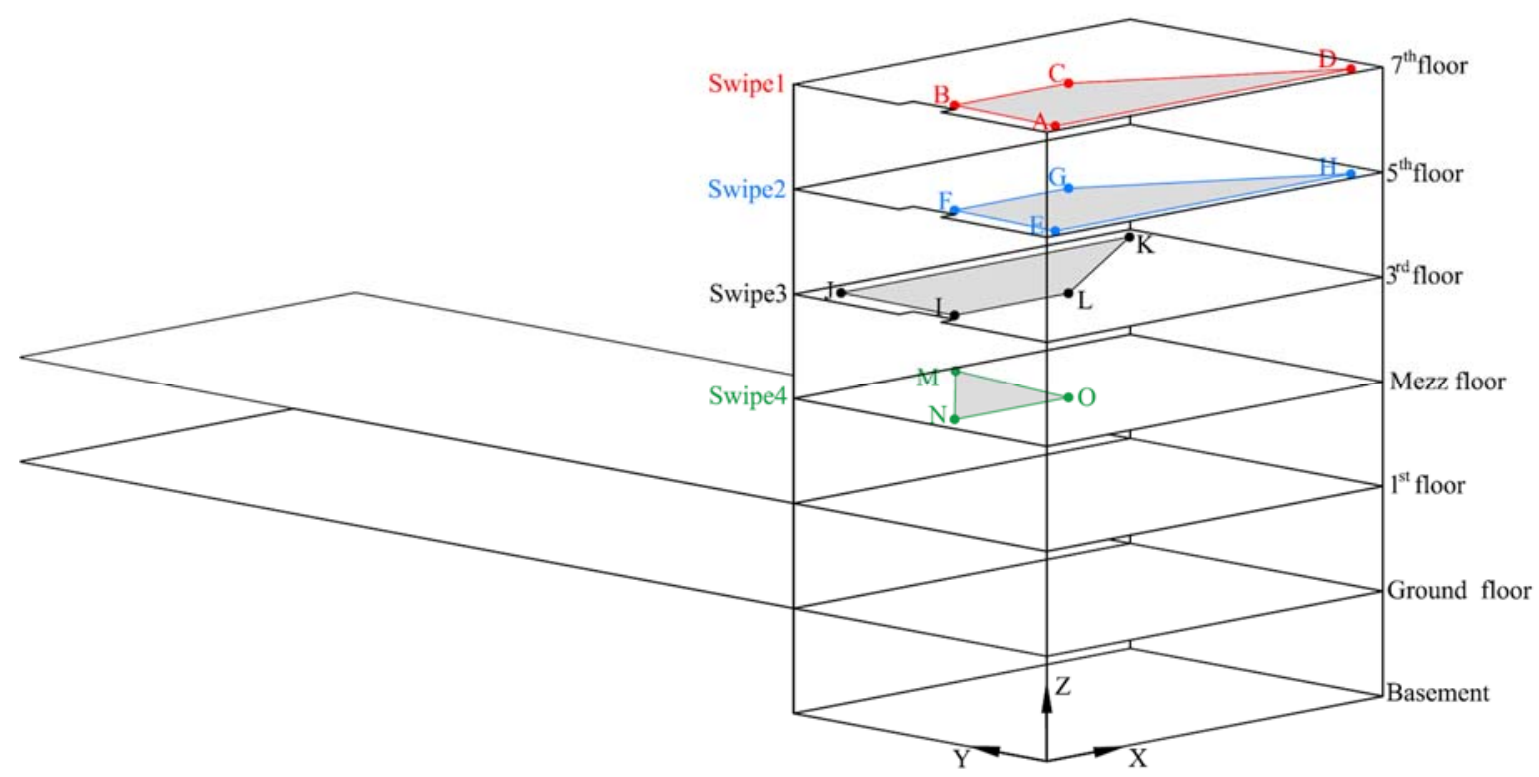

Fig. 12, 3D schematic of the tower with the test points on each floor indicated. 


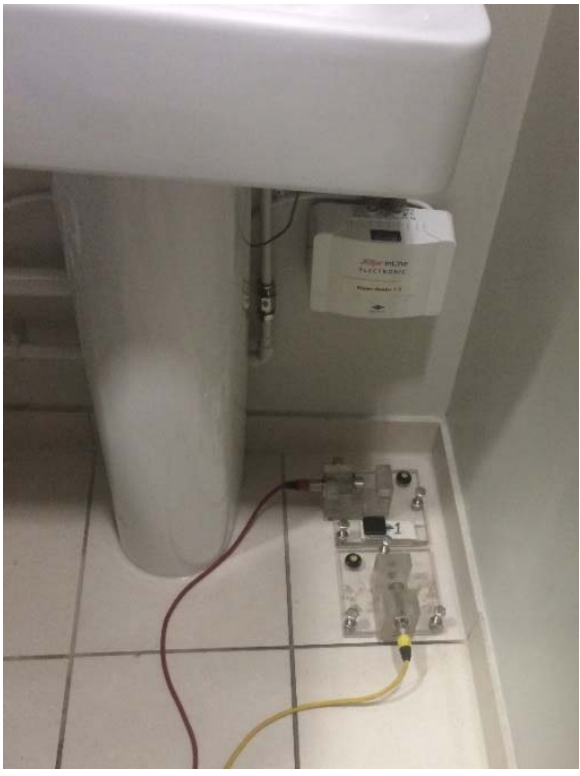

(a)

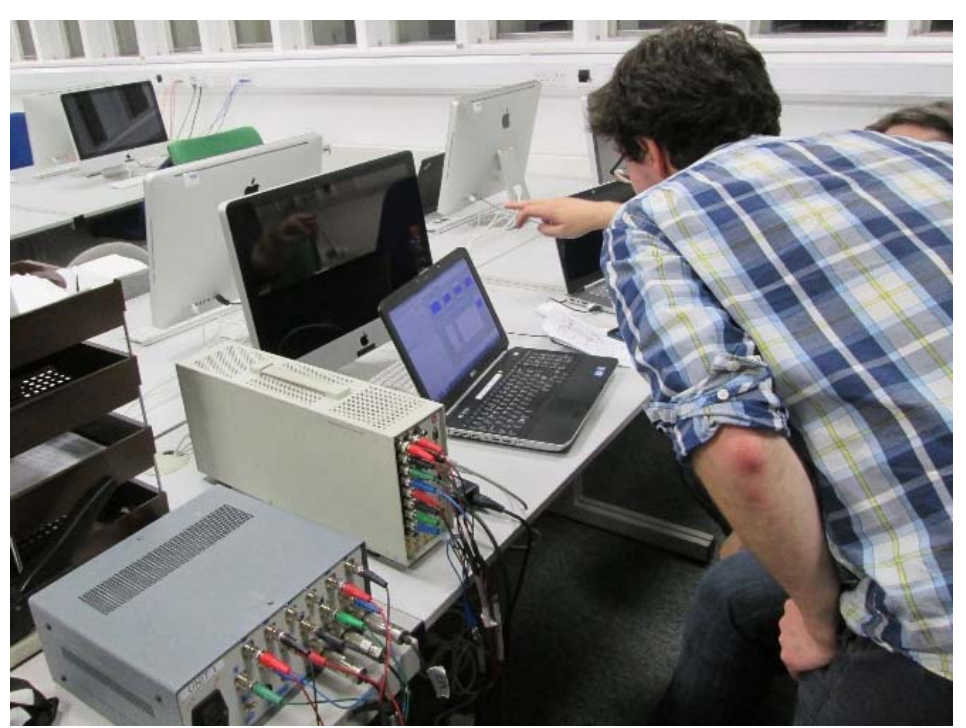

(b)

Fig. 13, (a) two QA accelerometers and one IMU sensor at test point $A$ on the $7^{\text {th }}$ floor (b) data acquisition

Fig. 14 shows the signals recorded at test point $A$ (the reference location on the $7^{\text {th }}$ floor) during swipe 1 , with parts (a) and (b) showing the acceleration in the $x$ and $y$ directions respectively. The first thing to notice about Figs. 14 (a) and (b) is that the noise floor for the QA's is much lower than for the IMUs, reflecting the result shown in Fig. 2. On the night of the test there was almost no wind so the tower was moving very little and as a result in the first 750 seconds (i.e. the first half) of the swipe the IMU signal is essentially just noise. However, the noise floor of the QA accelerometer is sufficiently low that it is picking up the tower vibrations. The difference in the performance of the both sensors in the first 750 seconds can be seen more clearly in the frequency domain. Figs. 15 (i) \& (ii) respectively show the result of analysing the first 750 seconds of the signals shown in Figs. 14 (a) \& (b) with the Welch method, window lengths of 120 seconds with a $50 \%$ overlap were used. It can be seen in Figs. 15 (i) \& (ii) that the QA's are identifying frequencies of $2.5 \mathrm{~Hz}$ and $2.1 \mathrm{~Hz}$ in the $\mathrm{x}$ and $y$ directions respectively but that the IMU is not capturing these frequencies.

In an attempt to excite the tower sufficiently that the magnitude of the vibrations would be above noise floor of the IMUs it was decided to try excite the structure with three people stepping laterally from foot to foot at the building frequency. To excite a lateral frequency of $2.1 \mathrm{~Hz}$ required the authors to step laterally at a rate of 4.2 steps per second. To achieve this rhythm an audio metronome was set to 252 beats per minute and the three authors stepped/jumped at this rate on the $7^{\text {th }}$ floor of the building. Fig. 16 shows an image of the authors jumping, note in this image the authors shoulders are parallel with the $y$ axis of the building. The large pulses in acceleration at approximately 1100 seconds in Fig. 14 (a) \& (b) are as a result of this jumping. The zoomed in view shown in Fig. 14 (c) \& (d) shows clear sinusoidal signals for both the IMUs and QAs and it can be seen that the signals from the IMUs agree very well with the signals from the QA's.

Once the $2.1 \mathrm{~Hz}$ mode had been excited the authors realigned so that they were standing one behind the other but now their shoulders were parallel with the buildings $x$ axis. To excite $a$ 
frequency of $2.5 \mathrm{~Hz}$ required the authors to step at a rate of 5 steps per second. The pulses in IMU acceleration visible in Fig. 14 (a) \& (b) at approximately 1400 seconds are as a result of this stepping/jumping. However, it should be noted that the authors found 5 steps per second towards the upper end of what was physically possible and it would be impossible to excite higher modes using this technique. The reason the IMU time series in Fig. 14(a) and Fig. 14(b) is a little longer than the QA time series is that the data logger recording the QA signals had been programmed to automatically stop recording after 24 minutes, so the QAs just missed the jumping/stepping in the $x$ direction.

Figs. 15(iii) and (iv) respectively show the frequency content of the signals that were recorded during the jumping phase of the test, i.e. the signals in the latter half of Fig. 14(a) and (b), from 750 seconds onwards. Unlike Figs. 15(i) and (ii) when the IMU data were unable to capture the building frequencies in Figs. 15(iii) and (iv), the building frequencies are clearly evident in the IMU data. Once it had been shown that the IMUs could capture the tower frequencies provided the building was excited by humans jumping this procedure was also followed for Swipes 2-4. At the end of each swipe all five IMUs were brought together to allow them to resynchronise if they had lost synchronisation. The mode shapes identified from both the QA and IMU data are presented in section 5.4.
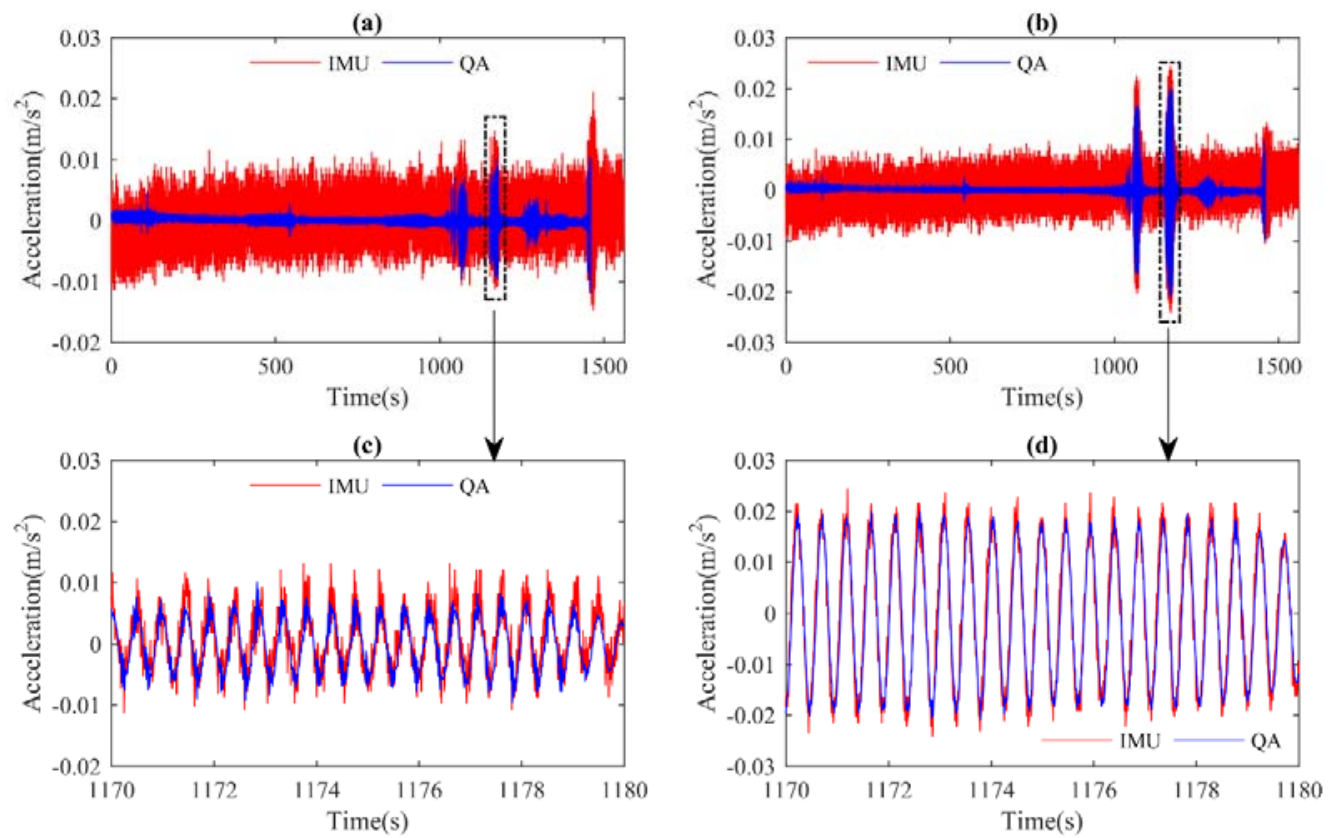

Fig. 14 Acceleration recorded at reference location (test point A) during swipe 1, (a) acceleration in $x$-direction (b) acceleration in y-direction, (c) zoomed in in view at 1170 seconds (d) zoomed in in view at 1170 seconds 

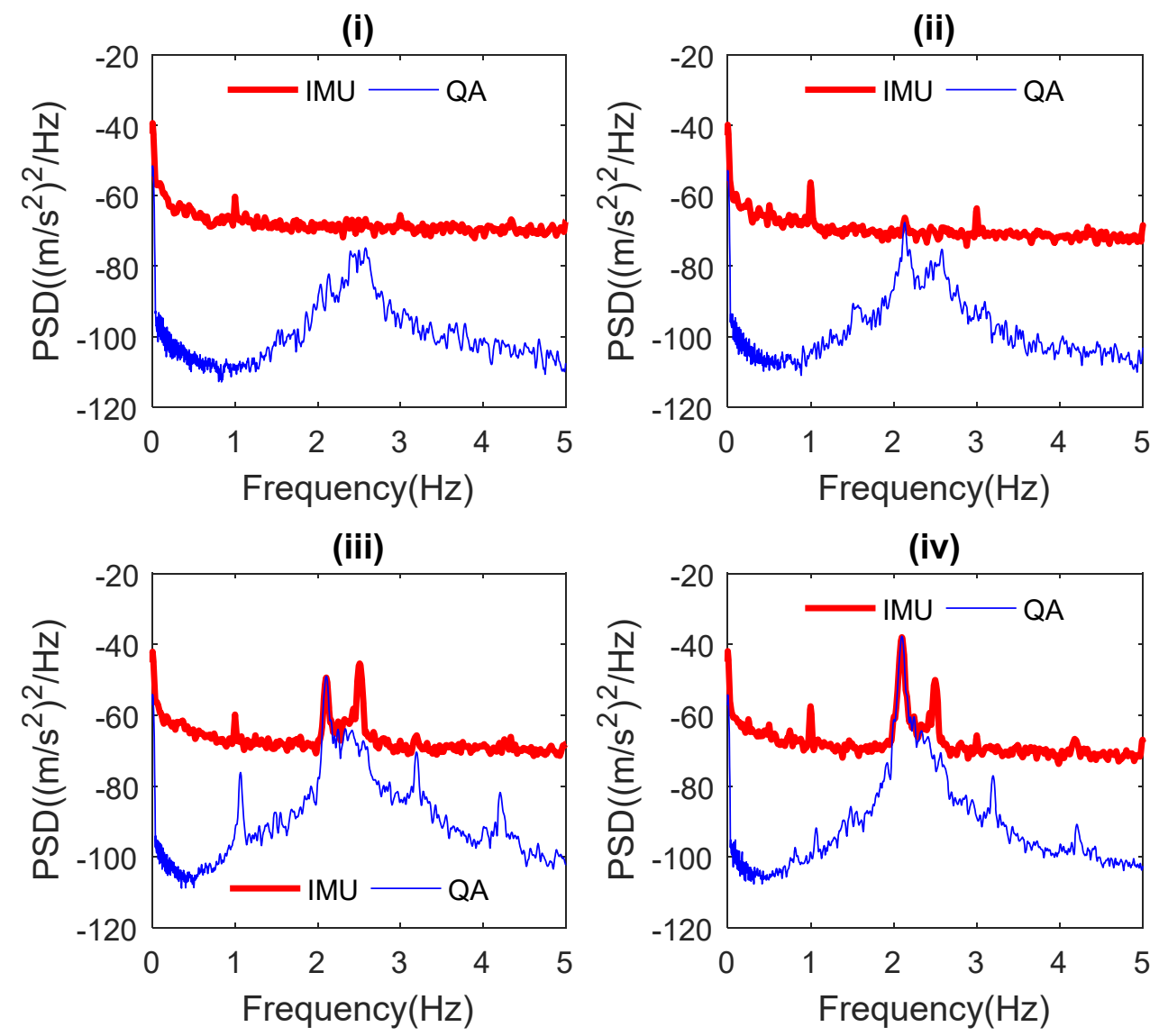

Fig. 15, Frequency content of the signals shown in Fig. 14, (i) frequency content of the first 750 seconds of acceleration data shown in Fig. 14(a), (ii)frequency content of the first 750 seconds of acceleration data shown in Fig. 14(b), (iii) frequency content of second half of the IMU acceleration signal shown in Fig. 14(a) i.e. after 750 seconds, (iv) frequency content of second half of the IMU acceleration signal shown in Fig. 14(b) i.e. after 750 seconds. 


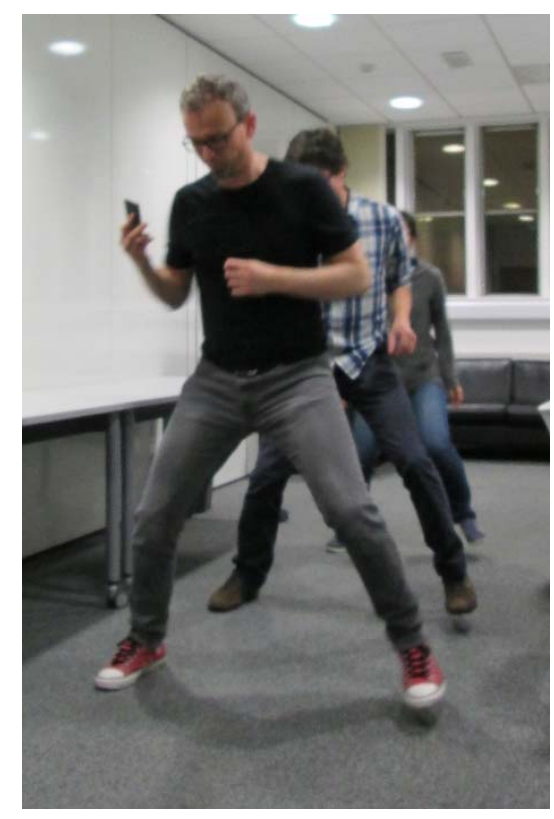

Fig. 16, three of the authors stepping laterally to a predetermined beat on the $7^{\text {th }}$ floor to excite building motion.

\subsection{IMU Synchronisation}

Prior to carrying out modal identification on the tower data, the amount of time drift that occurred between the different IMUs was investigated. As explained in Section 2.2 each IMU has its own internal clock and the data recorded at a given time instant is time stamped against the time on the internal clock. When operating in SLM, if the IMUs remain within range of each other the timing of each internal clock is adjusted according to a probabilistic model, so the time on all the clocks remains identical and therefore the data from each IMU is synchronised. Once an individual IMU sensor is out of range of its companions in the network, then the clock in that IMU is running independently so there is a possibility that it will start to run slightly ahead, or slightly behind the internal clocks of the other IMUs. The likelihood of the clock of the isolated IMU starting to run slightly ahead/behind the clocks of the other IMUs in increased if the isolated sensor is placed in a significantly different temperature to the other IMUs in the network. Once all the IMUs are reunited, i.e. that all five are within wireless range of each other, the probabilistic timing model will engage and identify what it considers the 'correct' time. Then the clock of any IMU not reading the correct time will be adjusted forwards or backwards such that it is reading the correct time. This occasional correcting of the time on the internal clock can be seen in post processing by examining the time stamps from the IMUs. The IMUs were scanning at $128 \mathrm{~Hz}$ so consecutive clock readings increase by 0.0078125 seconds, henceforth known as one time increment. However, if the clock in an isolated IMU has started to run a little 'slow', when the isolated IMU is brought back to the rest of the network it's clock will increment by two (or possibly three) time increments in a single step to bring that clock into line with the other clocks in the network. Alternatively if the clock in the isolated IMU had started to run 'fast', when it is reunited with its companions in the network the timestamp may increment by zero between consecutive steps, or possibly even show a negative increase if it is two or more time increments out of synchronisation. 
While the procedure described above (i.e. looking at the time stamps of individual IMUs) can be used to identify potential drift. When dealing with a network of five IMUs it is more meaningful to take the time stamp from one IMU as the reference, and compare the timestamps of the other four IMUs to the reference timestamp. Fig. 17 shows the result of carrying out such an exercise. IMU No 5 was taken as the reference and its timestamp was compared to the timestamps of IMUs No's 1-4 and the result of this comparison is shown in Figs. 17(a-d) respectively. It should be noted that the IMUs were recording from the start of the test until the end, i.e. IMU recording is not stopped between swipes, instead the swipe data (for the four individual swipes) is cut from the total IMU time series in post processing. In Fig 17(a) it can be seen that in total the IMUs were recording for approximately 240 minutes and that in this period IMU No 1 only drifted from IMU No 5 by one time increment and this occurred after 163 minutes. Parts (b), (c) and (d) of the figure also show some drift at 163 minutes. As described in section 5.2, all five IMUs are all together at the start of a swipe for at least two minutes, and the steps/drifts apparent at 163 minutes is evidence of the probabilistic timing model 'correcting' the time on the internal clocks when the IMUs are reunited after a period of separation for one or more of the IMUs. Other occasions where a step change is observed in the timing of multiple sensors occur at 64 minutes and 112 minutes. Each of the swipes were 24 minutes long, and it can be seen from Fig. 17 that in any given 24 minute period there is never more than two increment drift in the internal clocks of the IMUs. This equates to a maximum drift of approximately 0.0156 seconds $(2 * 0.0078125 \approx 0.0156)$. When one is dealing with frequencies less than $10 \mathrm{~Hz}$ (period $\geq 0.1$ seconds) even if an individual IMU goes out of synchronisation with the other sensors in the network by one time step (0.0078 s) or even two time steps (0.0156 s) over the course of a 24 minute swipe it effects the phase very little and as a result the mode shapes will still be correct. The timestamps of the individual IMUs were also checked after the modal test on the bridge (Section 4) however, for the bridge test there were zero slips evident. This is believed to be due to the fact that during the bridge test the IMUs were sufficiently close together to maintain mesh synchronisation in SLM for the duration of the bridge test. 

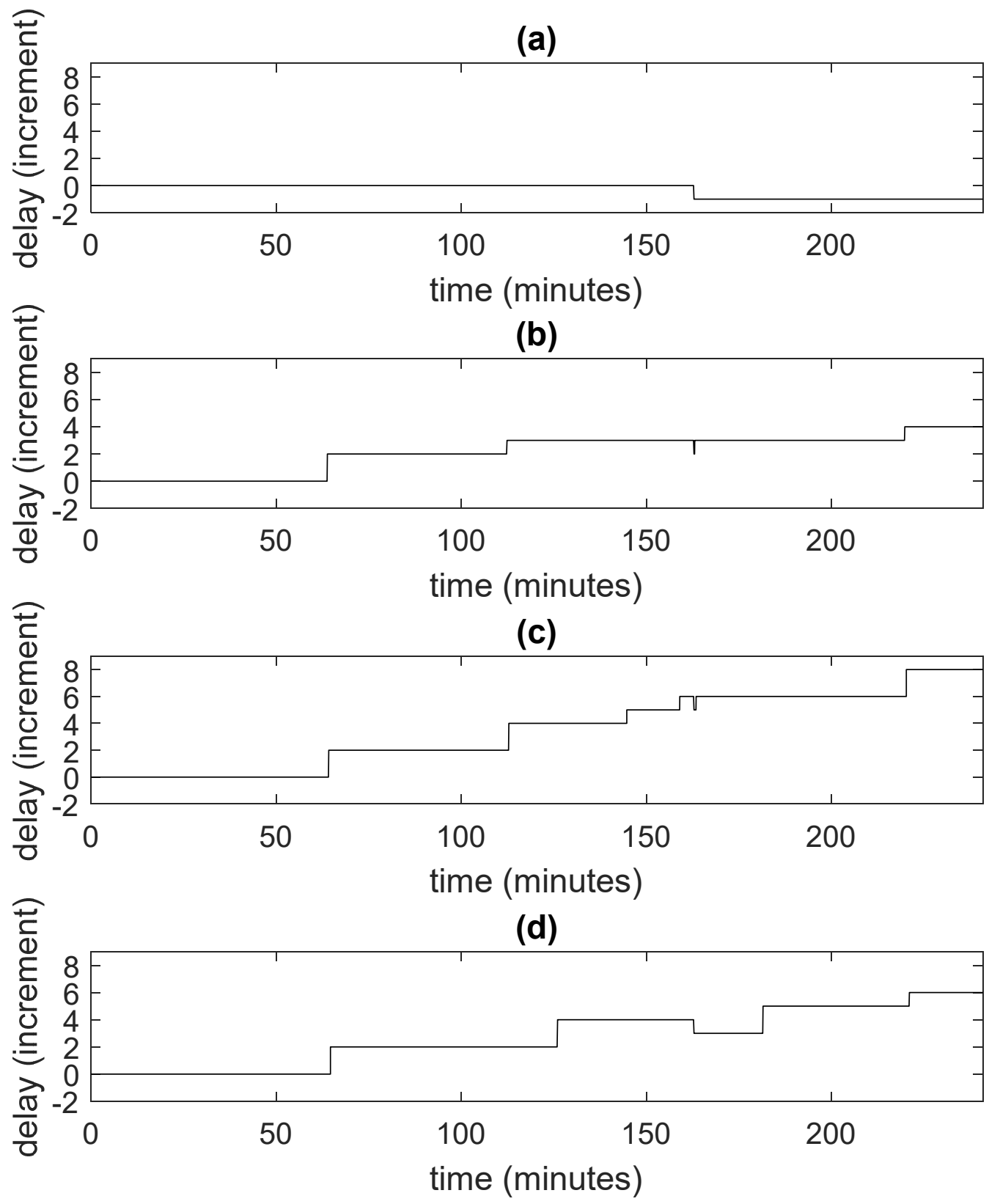

Fig. 17 Variation between the internal clock of the reference IMU (IMU No 5) and the internal clocks of the other four IMUs in the network (a) Difference between the reference clock and IMU No 1, (b) Difference between the reference clock and IMU No 2, (c) Difference between the reference clock and IMU No 3, (d) Difference between the reference clock and IMU No 4. 


\subsection{Mode shapes from tower}

Having satisfied ourselves that synchronisation will not be a significant problem, the modal identification procedure described in section 3.2.2 was implemented to identify the mode shapes from both the QA and IMU data and the results are shown in Table 4. The stick model in Table 4 can be understood if the sensor layout in Fig. 12 is examined. For modes 1 and 2 the mode shapes and frequencies calculated using the IMU sensors compare very well with those calculated using the wired QA system. However, mode shape 3 is not correctly identified from the IMU data. This may have been because the amplitudes of vibration associated with the third mode were simply so small that they were not detected properly by the accelerometer in the IMU, or it may be that for higher frequencies and therefore lower periods of vibration are more sensitive to time drift between individual IMUs if mesh synchronisation is lost during the swipe. However, the fact that modes 1 and 2 are identified correctly in the IMU data is relatively impressive for two reasons. Firstly even with the jumping the magnitude of the acceleration was still quite small with the maximum amplitudes on the $7^{\text {th }}$ floor in the region of $0.01-0.02 \mathrm{~m} / \mathrm{s}^{2}$ with even smaller amplitudes on the lower floors. Secondly for swipes 2-4 there were significant distances and obstructions between the IMUs on the floor being measured and the reference IMU on the $7^{\text {th }}$ floor.

It is important to note that without having the QAs on site the night of the test it would have been very difficult for the authors to know what frequencies to jump at to excite the structure. If the authors only had IMU's on the night they would have had to jump at a series of different frequencies in the range of frequencies expected for the building, to see which provide the best excitation and this would have been very slow. However, as noted earlier on the night of the test the weather was extremely calm so a small follow up test was carried out on a windy night to see if the IMUs could capture the structural frequencies (without anyone jumping), and the results of this test are briefly reported in the next section. 
Table 4, Frequencies, damping coefficients and mode shapes for the first 3 tower modes

\begin{tabular}{|c|c|c|c|}
\hline & Mode 1 & Mode 2 & Mode 3 \\
\hline QA & Freq $=2.11 \mathrm{~Hz}$ & Freq $=2.5 \mathrm{~Hz}$ & Freq $=10.8 \mathrm{~Hz}$ \\
\hline & Damping $=0.44 \%$ & Damping $=0.68 \%$ & Damping $=0.071 \%$ \\
\hline \multirow[t]{3}{*}{ IMU } & Freq $=2.11 \mathrm{~Hz}$ & Freq $=2.52 \mathrm{~Hz}$ & Freq $=10.7 \mathrm{~Hz}$ \\
\hline & Damping $=0.3 \%$ & Damping $=0.4 \%$ & Damping $=0.51 \%$ \\
\hline & $\begin{array}{l}\mathbf{0 \%} \text { difference between IMU } \\
\text { and QA Frequency }\end{array}$ & $\begin{array}{l}0.79 \% \text { difference between } \\
\text { IMU and QA Frequency }\end{array}$ & $\begin{array}{l}0.93 \% \text { difference between } \\
\text { IMU and QA Frequency }\end{array}$ \\
\hline
\end{tabular}

\subsection{Limited testing on windy night}

To see if the IMUs might be able to pick up the building frequencies without people jumping, a limited test with just one IMU was carried out on a night with winds of approximately $20 \mathrm{mph}$. The IMU was positioned on the $7^{\text {th }}$ floor at test point $C$ indicated in Fig. 11(a). Fig. 18(a) shows the acceleration recorded in the $x$ and $y$ directions as solid and dashed plots respectively. Fig. 18(b) shows the frequency content of the signals between 1.5 and $5 \mathrm{~Hz}$ and it can be seen that the structural frequencies at 2.1 and $2.5 \mathrm{~Hz}$ are clearly visible. Therefore when there is sufficient wind to excite the structure the IMUs are able to pick up the building frequencies without specific human excitation. 

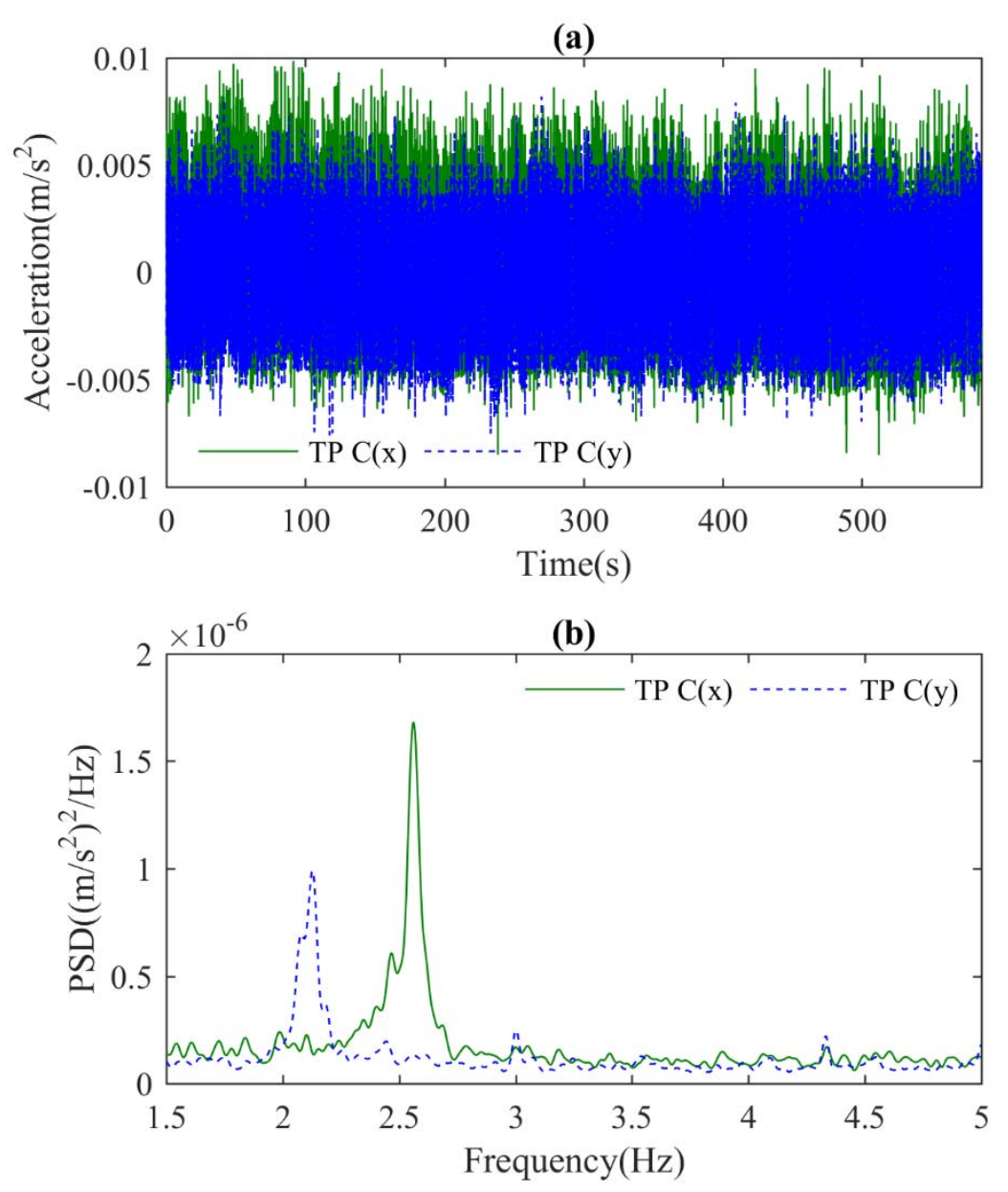

Fig. 18, Data recorded at test point $C$ on the $7^{\text {th }}$ floor on a night when there was $20 \mathrm{mph}$ wind (a) time series data, (b) frequency content of acceleration data shown in (a).

\subsection{Discussion and conclusions}

In this study it was found that the mode shapes identified for the three structures using IMU acceleration data, were very similar to the corresponding mode shapes identified from the QA acceleration data. Admittedly for the modal test of the concrete office tower there were some instances where the QAs were superior but these aspects are further discussed below.

For the floor structure in the laboratory the IMUs were never more than a few meters apart so no problems with synchronisation were envisaged and indeed this proved to be the case as the IMUs performed just as well as the QAs. In the laboratory there was ready availability of power, the logging station could be set up wherever was convenient and there was no restrictions on where cables could be ran. Therefore while the IMUs were still quicker to set up than the QAs the difference was not that pronounced and any time advantages for the IMUs in the set up were at least partially offset by the extra time required in post processing to cut the data for the 12 swipes from the total IMU time record.

However, the test on the steel road bridge really highlighted the potential benefits of the IMUs. Two 
of the basic requirements when setting up a logging station are electrical power and shelter from the elements. Unlike in a building where these things are readily available, on a bridge site these need to be provided/installed and this takes significant time. Installing the necessary cabling also takes a significant amount of time for three principle reasons;

(i) bridge remaining open: during a modal test on a bridge, the bridge will normally remain open to vehicle and pedestrian traffic which places limitations on where cables can be placed, thereby forcing the tester to position the cables in zones with more difficult access, which slows the process down,

(ii) length of cable required: the physical size of a real bridge means that tens to hundreds of meters of cable need to be installed,

(iii) challenging access: depending on the height of the deck, what passage the bridge is crossing, limited access to abutments, revetments etc. means it can be difficult/slow to get to the places cables need to be installed.

As a result planning and executing the wired test took over one hundred man hours, gathering the same information with the IMUs took approximately ten man hours. After processing the data, the mode shapes from the IMU data were the same as the mode shapes from the QA data. This shows that for the bridge tested the accelerometers in the IMUs were sensitive enough to accurately capture the vibrations and that synchronisation between the IMUs was adequate.

The structure where the IMUs struggled a bit was the tower. Prior to the tower test the authors' primary concern was that in the tower, the IMUs would not have clear lines of sight between each other for wireless communication and therefore one or more sensors might drift (in time) significantly from the others and as a result the IMUs' signals might not be time synchronised. However, this did not prove to be such an issue. Instead it was found that for very low levels of vibration the noise floor in the IMUs accelerometer is simply too high to allow accelerations to be identified so it was necessary for the authors to artificially induce acceleration at a level high enough for the IMUs to detect it. If the test had been carried out on a windy night it appears from section 5.5 that the IMUs would not need human induced vibrations as the wind is sufficient to excite the structure. Essentially the tower test showed that the primary limitation of the IMUs for structural modal testing is the quality of the accelerometer rather than issues with synchronisation.

From the three structures tested it was shown that over the course of a 20-30 minute swipe (commonly used for a modal test on a structure) the IMUs did not drift significantly in time. This means that if a more sensitive accelerometer was used they really could be very useful for structural modal testing, particularly on bridge sites. However, if one was going to change the accelerometer it would make sense to make the units a little bigger, and install the hardware necessary to increase the range of the wireless capabilities so that the sensors could remain in wireless communication over longer distances and therefore remain mesh synchronised. 


\section{Acknowledgements}

The research leading to these results has received funding from the People Programme (Marie Curie Actions) of the European Union's Seventh Framework Programme (FP7/2007-2013) under grant agreement $n^{\circ} 330195$. The authors would also like to acknowledge the Bridge Section of The Engineering Design Group of Devon County Council led by Kevin Dentith BSc, CEng, FICE, for their support and assistance with this work.

\section{References}

[1] P. Moyo, J.M.W. Brownjohn, P. Omenzetter, Highway bridge live loading assessment and load carrying estimation using a health monitoring system, Struct. Eng. Mech. 18 (2004) 609-626.

[2] F.N. Catbas, T. Correa-Kijewski, A.E. Aktan, Structural Identification of Constructed Systems. Approaches, Methods and Technologies for Effective Practice of St-Id., ASCE, 2013.

[3] S. Jang, H. Jo, S. Cho, K. Mechitov, J. a Rice, S.H. Sim, H.J. Jung, C.B. Yun, B.F. Spencer, G. Agha, Structural health monitoring of a cable-stayed bridge using smart sensor technology: deployment and evaluation, Smart Struct. Syst. 6 (2010) 439-459. doi:10.12989/sss.2010.6.5_6.439.

[4] S. Jang, S.-H. Sim, H. Jo, B.F. Spencer Jr, Full-scale experimental validation of decentralized damage identification using wireless smart sensors, Smart Mater. Struct. 21 (2012) 115019. doi:10.1088/0964-1726/21/11/115019.

[5] G.L. Smidt, R.H. Deusinger, J. Arora, J.P. Albright, An automated accelerometry system for gait analysis, J. Biomech. 10 (1977) 367-375. doi:10.1016/0021-9290(77)90009-4.

[6] H.J. Luinge, P.H. Veltink, Measuring orientation of human body segments using miniature gyroscopes and accelerometers, Med. Biol. Eng. Comput. 43 (2005) 273-282. doi:10.1007/BF02345966.

[7] F. Brunetti, J.C. Moreno, A.F. Ruiz, E. Rocon, J.L. Pons, A new platform based on IEEE802.15.4 wireless inertial sensors for motion caption and assessment, in: Int. Conf. IEEE Eng. Med. Biol. Soc., 2006: pp. 6497-6500.

[8] M. Bocian, J.M.W. Brownjohn, V. Racic, D. Hester, A. Quattrone, R. Monnickendam, A framework for experimental determination of localised vertical pedestrian forces on full-scale structures using wireless attitude and heading reference systems, J. Sound Vib. 376 (2016) 217-243. doi:10.1016/j.jsv.2016.05.010.

[9] B. Peeters, W. Hendricx, J. Debille, Modern Solutions for Ground Vibration Testing of Large Aircraft, Sound Vib. 295 (2009) 8-15. doi:10.4271/2008-01-2270.

[10] A. Pavic, Z. Miskovic, P. Reynolds, Modal Testing and Finite-Element Model Updating of a Lively Open-Plan Composite Building Floor, J. Struct. Eng. 133 (2007) 550-558. doi:10.1061/(ASCE)0733-9445(2007)133:4(550).

[11] D.J. Ewins, Modal Testing: Theory, Practice and Application, Research Studies Press Ltd., Baldock, Hertfordshire, England, 2000.

[12] A.M. Abdel-Ghaffar, R.H. Scanlan, Ambient vibration studies of Golden Gate bridge: 1. Suspended structure, and 2. Pier tower structure, ASCE J. Eng. Mech. 111 (1985) 463-482. doi:10.1061/(ASCE)0733-9399(1985)111:4(463). 
[13] J.M.W. Brownjohn, E.P. Carden, C.R. Goddard, G. Oudin, Real-time performance monitoring of tuned mass damper system for a $183 \mathrm{~m}$ reinforced concrete chimney, J. Wind Eng. Ind. Aerodyn. 98 (2010) 169-179. doi:10.1016/j.jweia.2009.10.013.

[14] S.K. Au, Uncertainty law in ambient modal identification---Part II: Implication and field verification, Mech. Syst. Signal Process. 48 (2014) 34-48. doi:10.1016/j.ymssp.2013.07.017.

[15] PCB Piezotronics, PCB Piezotronics, (2017). http://www.pcb.com/Products/model/393c (accessed October 8, 2017).

[16] Honeywell, Q-Flex QA-750, (2017).

https://aerospace.honeywell.com/en/ /media/aerospace/files/brochures/accelerometers/qflexqa-750accelerometer_bro.pdf (accessed October 8, 2017).

[17] Kinemetrics, Episensor, (2017). https://kinemetrics.com/post_products/episensor-es-t/ (accessed October 8, 2017).

[18] L. Nachman, J. Huang, J. Shahabdeen, R. Adler, R. Kling, IMOTE2: Serious computation at the edge, Proc. IWCMC 2008 - Int. Wirel. Commun. Mob. Comput. Conf. (2008) 1118-1123.

[19] J. a. Rice, B.F. Spencer, Jr., Structural health monitoring sensor development for the Imote2 platform, Proc. SPIE - Int. Soc. Opt. Eng. 6932 (2008) 693231-693234. doi:10.1117/12.776695.

[20] M. Kane, D. Zhu, M. Hirose, X. Dong, B. Winter, M. Häckell, J.P. Lynch, Y. Wang, A. Swartz, Development of an extensible dual-core wireless sensing node for cyber-physical systems, in: SPIE - Int. Soc. Opt. Eng., 2014: p. 90611U. doi:10.1117/12.2045325.

[21] S. Cho, H. Jo, S. Jang, J. Park, H.J. Jung, C.B. Yun, B.F. Spencer, J.W. Seo, Structural health monitoring of a cable-stayed bridge using wireless smart sensor technology: data analyses, Smart Struct. Syst. 6 (2010) 461-480.

[22] D. Zhu, Y. Wang, J.M.W. Brownjohn, Vibration testing of a steel girder bridge using cabled and wireless sensors, Front. Archit. Civ. Eng. China. 5 (2011) 249-258. doi:10.1007/s11709-0110113-y.

[23] J. Li, T. Nagayama, K.A. Mechitov, B.F. Spencer, Efficient campaign-type structural health monitoring using wireless smart sensors, in: Proc. SPIE - Sensors Smart Struct. Technol. Civil, Mech. Aerosp. Syst., 2012: p. 83450U-83450U-11. doi:10.1117/12.914860.

[24] J.M.W. Brownjohn, F. Magalhães, E. Caetano, A. Cunha, Ambient vibration re-testing and operational modal analysis of the Humber Bridge, Eng. Struct. 32 (2010) 2003-2018. doi:10.1016/j.engstruct.2010.02.034.

[25] Guralp, MAN-RTM-0003 - Real-time Clock Operator's Guide, (2016).

[26] J.M.W. Brownjohn, S.K. Au, B. Li, J. Bassitt, Optimised ambient vibration testing of long span bridges, in: EURODYN 2017, 2017: p. 10. doi:10.1016/j.proeng.2017.09.147.

[27] Y.L. Xi, Y.C. Zhu, S.K. Au, Operational modal analysis of Brodie Tower using a Bayesian approach, in: UNCECOMP 2017 Int. Conf. Uncertain. Quantif. Comput. Sci. Eng., 2017: p. 10.

[28] K.Y. Wong, K.W.Y. Chan, K.L. Man, Monitoring of wind load and response for cable-supported bridges in Hong Kong, in: Proc SPIE 4337, Heal. Monit. Manag. Civ. Infrastruct. Syst., 2001: p. 12. 
[29] K. Lebel, P. Boissy, M. Hamel, C. Duval, Inertial measures of motion for clinical biomechanics: Comparative assessment of accuracy under controlled conditions - Effect of velocity, PLoS One. (2013). doi:10.1371/journal.pone.0079945.

[30] V. Krishnamurthy, K. Fowler, E. Sazonov, The effect of time synchronization of wireless sensors on the modal analysis of structures, Smart Mater. Struct. 17 (2008) 055018. doi:10.1088/0964-1726/17/5/055018.

[31] J.M.W. Brownjohn, M. Bocian, D. Hester, A. Quattrone, W. Hudson, D. Moore, S. Goh, M.S. Lim, Footbridge system identification using wireless inertial measurement units for force and response measurements, J. Sound Vib. 384 (2016) 339-355. doi:10.1016/j.jsv.2016.08.008.

[32] R. Sleeman, Three-Channel Correlation Analysis: A New Technique to Measure Instrumental Noise of Digitizers and Seismic Sensors, Bull. Seismol. Soc. Am. 96 (2006) 258-271. doi:10.1785/0120050032.

[33] S.K. Au, J.M.W. Brownjohn, J.E. Mottershead, Quantifying and managing uncertainty in operational modal analysis, Mech. Syst. Signal Process. 102 (2018) 139-157. doi:10.1016/j.ymssp.2017.09.017.

[34] J.M. Caicedo, Practical guidelines for the natural excitation technique (NExT) and the eigensystem realization algorithm (ERA) for modal identification using ambient vibration, Exp. Tech. 35 (2011) 52-58. doi:10.1111/j.1747-1567.2010.00643.x.

[35] C. Gentile, N. Gallino, Ambient vibration testing and structural evaluation of an historic suspension footbridge, Adv. Eng. Softw. 39 (2008) 356-366. doi:10.1016/j.advengsoft.2007.01.001.

[36] K. Van Nimmen, P. Van den Broeck, P. Verbeke, C. Schauvliege, M. Malli?, L. Ney, G. De Roeck, Numerical and experimental analysis of the vibration serviceability of the Bears' Cage footbridge, Struct. Infrastruct. Eng. 13 (2017) 390-400. doi:10.1080/15732479.2016.1160133.

[37] S.K. Au, Operational Modal Analysis: Modeling, Bayesian Inference, Uncertainty Laws, Springer, 2017.

[38] J.M.W. Brownjohn, H. Hao, T.-C. Pan, Assessment of structural condition of bridges by dynamic measurements Applied Research Report RG5/97, (2001) -.

[39] J.N. Juang, R.S PAppa, An eigensystem realization algorithm for modal parameter identification and modal reduction, J. of Guidance, 8 (2015) 620-627

[40] G.H. James, T.G. Carne, J.P. Lauffer, The natual excitation technique (NExT) for modal parameter extraction from operating structures, Journal of analytical and Experimental modal analysis, 10 (1995) 260-277

[41] P.D. Welch, The use of fast Fourier transform for the estimation of power spectra: A method based on time averaging over short, modified periodograms, IEEE Trans. Audio Electroacoust. 15 (1967) 70-73.

[42] H. Nandan, M.P. Singh, Effects of thermal environment on structural frequencies: Part I - A simulation study, Eng. Struct. 81 (2014) 480-490. doi:10.1016/j.engstruct.2014.06.046. 